Florida International University FIU Digital Commons

7-9-1999

\title{
AFM and SPR studies of protein adsorption at solid/liquid interface
}

Rafael Arechabaleta

Florida International University

DOI: $10.25148 /$ etd.FI14030206

Follow this and additional works at: https://digitalcommons.fiu.edu/etd

Part of the Physics Commons

\section{Recommended Citation}

Arechabaleta, Rafael, "AFM and SPR studies of protein adsorption at solid/liquid interface" (1999). FIU Electronic Theses and Dissertations. 1054.

https://digitalcommons.fiu.edu/etd/1054

This work is brought to you for free and open access by the University Graduate School at FIU Digital Commons. It has been accepted for inclusion in FIU Electronic Theses and Dissertations by an authorized administrator of FIU Digital Commons. For more information, please contact dcc@fiu.edu. 
FLORIDA INTERNATIONAL UNIVERSITY

Miami, Florida

\title{
AFM AND SPR STUDIES OF PROTEIN ADSORPTION \\ AT SOLID/LIQUID INTERFACE
}

A thesis submitted in partial fulfillment of the

\author{
requirements for the degree of \\ MASTER OF SCIENCE
}

in

\section{PHYSICS}

by

Rafael Arechabaleta

2000 


\section{College of Arts and Sciences}

This thesis, written by Rafael Arechabaleta, and entitled AFM and SPR Studies of Protein Adsorption at Solid/Liquid Interface, having been approved in respect to style and intellectual content, is referred to you for judgment.

We have read this thesis and recommend that it be approved.
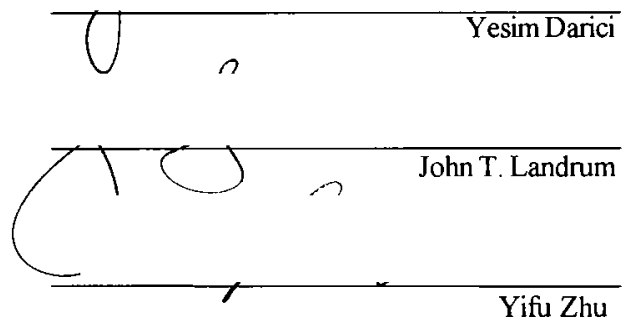

Date of Defense: July 9, 1999

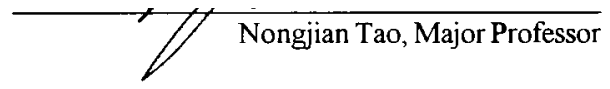

The thesis of Rafael Arechabaleta is approved.

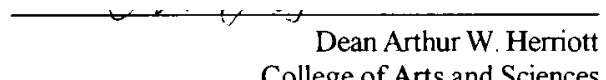

College of Arts and Sciences

Dean Richard L. Campbell

Division of Graduate Studies

Florida International University, 2000 


\section{DEDICATION}

Dedicated to my family and to the people that make possible to get this goal in my life. 


\section{ACKNOWLEDGMENTS}

I would like to thank Dr. Salah Boussad for his assistance, suggestion, and above all for the knowledge that I received working with him

Special thanks must go to my major professor, Dr. Nongjian Tao for having the confidence in me to do this project.

I would also like to express my gratitude to all the faculty and staff members in the Physics department, to Carlos Orta, W. L. Huang, and J. D'Agnese for their colaboration throughout my project, finally to the committee members for being in my defense. 


\title{
ABSTRACT OF THE THESIS
}

\section{AFM AND SPR STUDIES OF PROTEIN ADSORPTION}

AT SOLID/LIQUID INTERFACE

by

\author{
Rafael Arechabaleta
}

Florida International University, 2000

Miami, Florida

\section{Professor Nongjian Tao, Major Professor}

Membrane-like structure formed by surfactant molecules of didodecyldimethylammonium bromide (DDAB) on both HOPG and gold electrodes were studied with AFM and SPR techniques. The study shows that the thickness of the adsorbed layer of DDAB is strongly dependent on the concentration of the vesicle solution.

We have also investigated the adsorption of redox protein, Cytochrome $c$, on graphite electrode with in situ tapping mode AFM. The protein adsorbs spontaneously onto the electrode covered with an adsorbed phosphate layer and forms a uniform monolayer. The adsorbed protein exhibits a reversible electron transfer at $0.17 \mathrm{~V}$ $(\mathrm{Ag} / \mathrm{AgCl})$ once the electrode potential has been increased to $0.75 \mathrm{~V}$.

Using surface plasmon resonance spectroscopy we have measured subtle conformational change in protein, $\mathrm{Cyt} c$, due to electron transfer of a single electron on 
MPA-coated gold electrode. The electron transfer induced change in the resonant angle is about $0.006 \mathrm{deg}$, which corresponds to $\sim 0.2 \AA$ decreases in the thickness. This is consistent with that reduced state is more compact than the oxidized state. 


\section{TABLE OF CONTENTS}

I. INTRODUCTION

1.1 Significance of the Study

1.2 How to Study Protein Adsorption at Solid Surfaces?

1.3 Atomic Force Microscopy

1.4 Surface Plasmon Resonance Spectroscopy

1.5 Purpose of this work

II EXPERIMENTAL 13

2.1 AFM Experiment 13

2.2 Electrochemical Cell 13

2.3 SPR Setup 14

2.4 Ultra High Vacuum Thin Film Evaporator 18

$\begin{array}{ll}2.5 \text { Materials } & 19\end{array}$

III RESULTS AND DISCUSSION 20

3.1 AFM Study of DDAB Layer on HOPG 20

3.2 SPR Study of the Adsorption of DDAB onto Bare and Coated-SAM Gold Surfaces 24

3.3 Structural and Electron Transfer Properties of Cytochrome $c$ Adsorbed on Graphite Electrode Studied by in situ Tapping Mode AFM

3.3.a AFM study of adsorbed Cytochrome c monolayers 32

3.3.b Real time monitoring Cytochrome $c$ adsorption... 34

3.3.b Electron transfer reaction of adsorbed Cytochrome $c$ Electron Transfer Induced Conformational Changes in Redox ProteinsSPR

3.4 Electron Transfer Induced Conformational Changes in Redox Proteins Using SPR

IV CONCLUSIONS 46

$\begin{array}{ll}\text { LIST OF REFERENCES } & 48\end{array}$ 


\section{LIST OF FIGURES}

FIGURE

Figure 1.1. Interatomic Force between tip and sample

Figure 1.2. Otto-Kretscmann Prism Arrangement

Figure 1.3. Graphical Representation of matching wavevectors at a given angle of incidence

Figure 2.1. Schematic Representation of conventional SPR Set-up.

Figure. 2.2. Schematic Diagram of the High resolution SPR Set-up.

Figure 3.1. AFM Image of freshly cleaved HOPG surface in Tris- $\mathrm{HCl}$ buffer.

Figure 3.2. Self-assemble DDAB monolayer on HOPG from $\mathrm{DDAB}$ vesicle solution..(a) Tapping mode AFM of the DDAB monolayer in Tris buffer solution. (b) Height profile along the dashed line shown in (a). (c) A model of DDAB layer that explains the observed images

Figure 3.3. Self-assemble DDAB multilayer on HOPG from a DDAB vesicle solution. (a) Tapping mode AFM image of the DDAB layer in Tris buffer solution where the square outline the region where the DDAB molecules have been removed with the AFM tip. (b) Height profile along the dashed line shown in (a). (c) A model of the DDAB layer that explains to observed images.

Figure 3.4 Reflectivity vs. Angle of incidence for bare gold exposed to $\mathrm{DDAB}$ solution.

Figure 3.5.(a) Change of SPR position in angle vs. time for the adsorption of DDAB onto gold. (b) Concentration, thickness, and angular shift for layer of DDAB.

Figure 3.6.(a) Change of SPR position in angle vs. time for the adsorption of DDAB onto gold/ 1-dodecanethiol. (b)Concentration, thickness, and angular shift for layers of $\mathrm{DDAB}$ on $\mathrm{Au} / 1$-dodecanethiol. 
Figure 3.7 (a) Change of SPR position in angle vs. time for the adsorption of $\mathrm{DDAB}$ onto gold/ cystamine dihydrochloride. (b) Concentration, thickness, and angular shift for layers of DDAB on $\mathrm{Au} /$ cystamine dihydrochloride.

Figure 3.8 (a) Change of SPR position in angle vs time for the adsorption of DDAB onto gold (b) Concentration, thickness, and angular shif layers of DDAB on Au/MPA.

Figure 3.9 Tapping mode AFM images of Cytochrome $c(0.1 \mathrm{mM})$ adsorbed on graphite from $50 \mathrm{mM}$ phosphate buffer imaged in the buffer $(a, b)$ and in air $(c, d)$.

Figure 3.10. Tapping mode AFM images of graphite before (a), during (b) and after (c) a drop of $0.1 \mathrm{mM}$ Cytochrome $c$ into the sample cell containing $50 \mathrm{mM}$ phosphate buffer.

Figure 3.11. Cyclic voltammograms of graphite electrode in $0.1 \mathrm{mM}$ Cyt $c+50 \mathrm{mM}$ phosphate buffer recorded before (a) and after (b) cycling the potential to $0.75 \mathrm{~V}$.

Figure 3.12 Tapping mode AFM images of adsorbed Cytochrome $c$ at $0.15 \mathrm{~V}(\mathrm{a})$, during a potential cycle from $0.40 \rightarrow 0.75$ $\rightarrow 0.05 \rightarrow 0.75 \mathrm{~V}(\mathrm{~b})$ and at $0.75 \mathrm{~V}(\mathrm{c})$

Figure3.13. (a) SPR dip position and the simultaneously recorded cyclic voltammogram (cv, inset) for buffer. (b) Kinetics of adsorption of Cytochrome $c$ during the experiment. (c) SPR dip position and the simultanously recorded cyclic voltammogram (cv, inset) for Cytochrome $c$.

Figure 3.14. Kinetics of the electron transfer induced conformational change in Cytochrome $c$ inmobilized on MPA-coated gold electrode in $50 \mathrm{mM}$ phosphate buffer. (a) Response of the SPR dip position when stepping the potential from 0.3 to $-0.2 \mathrm{~V}$ and back to $0.3 \mathrm{~V}$ after staying at $-0.2 \mathrm{~V}$ for $10 \mathrm{~ms}$. The dashed lines are fitting with simple exponential functions. The inset: The current response during the potential stepping which illustrates the response time of the electrochemical cell. (b) Followed by the simple exponential change (dashed line), there is a slow nonexponential change in the SPRresponse. Note logarithmic scale is used for time in order to show the entire process clearly. 


\section{CHAPTER I \\ INTRODUCTION}

\section{1) Significance of the study}

A detailed understanding of the interaction of proteins with surfaces is important for many applications. For example the adsorption of proteins onto surfaces is a central concern in systems where artificial materials contact biological fluids. This includes prostheses, dwelling sensors and catheters $[1,2]$. Protein interactions play a key role in embriogenesis, regulation of metabolism and the design of biocompatible materials for surgical implants [2,3]. One important application is that of biosensors where proteins play a role in surface recognition and charge transport. Metalloproteins are suitable for the second role because of their desirable electron transfer properties.

Cytochrome $c$ is a redox protein whose main function is to shuttle electrons between two membrane-bound enzymes in mitochondria. An important question that is directly related to the electron transport function of this protein is whether there is a large conformational difference between the oxidized and reduced states of

cytochrome $c$ [4-10]. We present a time-resolved High-Resolution Surface Plasmon Resonance (H-RSPR) study of the electron transfer reaction induced conformational changes in cytochrome $c$ immobilized on thiol-coated gold electrodes. We have also studied the adsorption of Didodecyldimethylammonium Bromide (DDAB) mono- and multi-layers on bare and thiol-coated gold surfaces [11-i3]. In the development of biosensors, for instance, a critical step is to immobilize proteins with intact functions onto the surface of a transducer. Although many proteins spontaneously adsorb onto solid surfaces, the adsorbed proteins often denature or adapt undesirable orientations on the 
surfaces. To remedy these problems, many methods have been developed, each with its own advantages and disadvantages.

A widely used method is to coat an electrode with a layer of organic molecules. If appropriate molecules are chosen, the layer can serve both as a cushion that prevents adsorbed proteins from denaturation and as a guide for the proteins to adapt a desirable orientation. A novel extension to this method uses alkylthiol monolayers on $\mathrm{Au}$ electrodes. The alkylthiols are known to self-assemble into ordered monolayers, with the thiol end anchored onto $\mathrm{Au}$ or $\mathrm{Ag}$ electrodes. An appropriate functional group on the opposite end can bind a protein, thus immobilizing it to the electrode.

More recently, membranes of surfactants and natural lipids have been used to coat electrodes by self-assembly or Langmuir-Blodgett methods. DDAB double layers mimic the physiological environment of many membrane-associated proteins. They provide not only an effective way to immobilize proteins onto electrodes for biosensor applications, but also nice model systems for studying the biological functions of proteins. The latter point is more important because studying proteins in vivo is rather difficult.

\section{2) How to Study Protein Adsorption on Solid Surfaces?}

A fast analytical method, capable of examining the adsorption of proteins at surfaces, would aid in understanding the mechanism of these processes. Surfaces with well-defined properties are required in order to create model systems for studying this adsorption $[1,2,11-14]$. Several sensing techniques exist and have been used for in situ and real-time monitoring of the adsorption of various molecules at the solid-liquid 
interface. Each method offers specific advantages such as time and spatial resolution. There are many studies that describe some of these techniques, which include solution depletion $[14,15]$, gravimetry $[14,16]$, hydrodynamic $[14,17]$, electrical, and optical techniques $[1-4,14]$. The most promising techniques include ellipsometry [18], Surface Plasmon Resonance (SPR) $[1,2,14,19,20]$, surface resistivity $[21,22]$ and Scanning Probe Microscopy (AFM and STM) $[3,11,23-25]$.

In this work we will use some of the techniques available to study the adsorption of Cytochrome $c$ and $\mathrm{DDAB}$ on graphite and $\mathrm{Au}(111)$, respectively. The methods of choice are in accordance with the desired information (number of molecules per unit area, dielectric constant and thickness of the adlayer) to be obtained from the measurements. The most direct way of observing the adsorption of both DDAB and Cytochrome $c$, is by means of microscopy. In our case we will use AFM to measure the thickness of both the adlayer of the surfactant and Cytochrome $c$. We will also use SPR, which depends on the change of the index of refraction to investigate the adsorption of Cytochrome $c$ and DDAB at the metal-liquid interface.

\section{3) Atomic Force Microscopy:}

Binning, Quate and Gerber $[23,24]$ developed the Atomic Force Microscope (AFM) in 1986 after inventing the Scanning Tunneling Microscope (STM) in 1978. AFM works for both conductive and insulating materials, and it, thus, overcomes the limitation of the STM for conductive samples only. This is an extremely important development for biological applications because it allows biological samples to be imaged under conditions that are similar to the native physiological conditions. Many 
biological samples have been examined, from DNA to proteins $[3,4,25]$. In addition to the biological applications, AFM has been used to examine the degradation of polymers, determine the movement of individual atoms, and fabricate metallic nanowires.

The operation of AFM $[23,24]$ is based on the following principle: A sharp tip mounted at the end of a cantilever is scanned over the surface using a feedback system. The feedback controls the piezo-electric scanner in order to maintain either a constant force or distance during the scanning. The force between the tip and the sample causes the cantilever to bend that is measured with a position sensitive photodetector. AFM has three basic operation modes: contact. non-contact and tapping mode, each has its advantages and disadvantages.

Figure 1.1 shows the force on the cantilever as a function of the distance between the tip and the sample. Below the $\mathrm{x}$-axis, the force is the attractive, which is due to the van der Waals force. When the force is controlled in this attractive force region, the AFM is operated in the non-contact mode. Above the $\mathrm{x}$-axis is repulsive force region where the AFM operates in contact or tapping mode. 
Repulsive Force

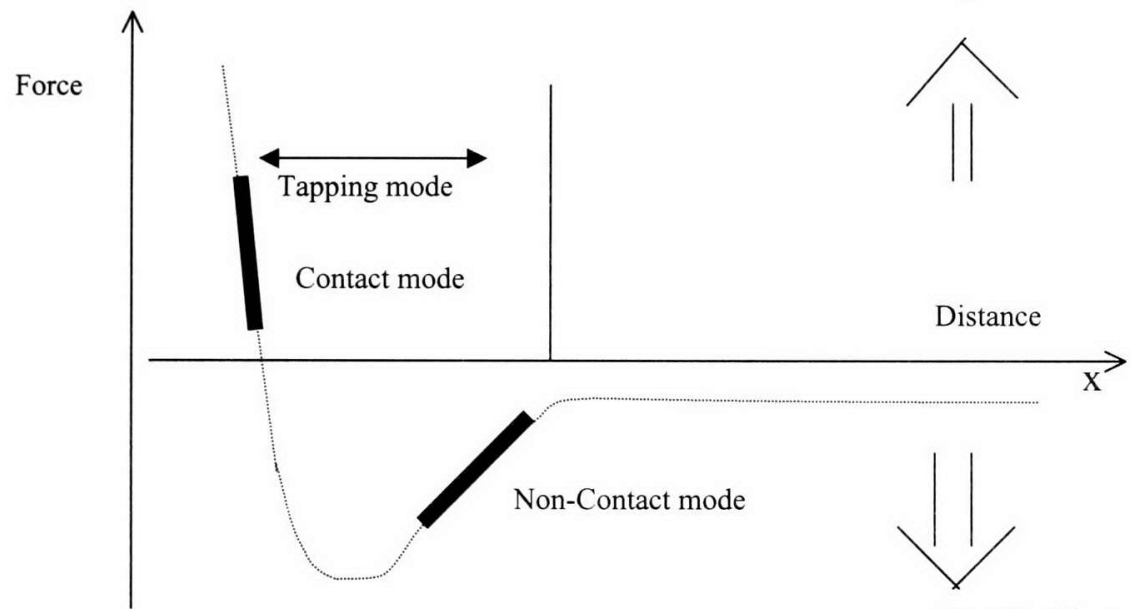

Attractive Force

Figure 1.1 A typical force-distance curve between the cantilever tip and the sample. 
Most AFM operates in contact mode where the tip moves against the repulsive "hard core" potential of the substrate. When operated in this mode, the large repulsive force often damages soft biological materials $(1-10)$. In the non-contact mode, the cantilever is held above the sample surface at about ten to one hundred of $\mathrm{nm}$. The cantilever is then vibrated near its resonance frequency. This principle is well described by Quate [23], and merits a brief discussion.

The force $\mathrm{F}$, applied to the end of the cantilever is related to the cantilever spring constant $(K)$ and displacement $(\mathcal{A})$

$$
F=K \Delta z
$$

The resonant frequency, $\omega_{0}$, of the cantilever with an effective mass of $m_{0}$, is given by the following relation,

$$
\omega_{0}=\sqrt{\frac{K}{m_{0}}}
$$

This relation is valid only when the force at the end of the cantilever does not vary along the $z$-axis. However, the applied force in general does vary with the distance between the tip and the sample. Thus, the resonant frequency of the cantilever changes according to

$$
\omega_{r}=\omega_{n}-\sqrt{\frac{1}{m} \frac{\partial F}{\partial z}}
$$


The change of the resonant frequency can be used to control the spacing between the tip and the sample, hence the force.

In tapping mode the change of both amplitude and phase of the cantilever are recorded. Due to short contact time, damage to both the tip and the sample is much less, compared to contact mode. This is one of the reasons the tapping is the most commonly used mode for imaging biological samples.

\section{4) Surface Plasmon Resonance Spectroscopy:}

The SPR phenomenon has been known for over 25 years and the theory is fairly well developed [20]. At the same time SPR studies have been widely applied to gas sensing, as well as to the study of the kinetics of adsorption in situ and in real time. It allows the evaluation of the thickness of the adsorbed layers on the metal surface. A surface plasmon (SP) represents the quanta of the oscillations of surface charges produced by exterior electric field in the boundary of a conductor, such as $\mathrm{Au}$ or $\mathrm{Ag}$. Surface plasmons can be excited also in semiconductors. The most common method of exciting plasmons is to couple the transverse-magnetic polarized energy (p-polarized) contained in an evanescent field to the plasmon mode on the metal film. In other words, SPR is observed when the wave vector of the external electric field (light incident on the surface) and wave vector of the surface plasmons are coupling. SPR is observed by measuring the change in the intensity of p-polarized reflected light using the prism arrangement, known as the Otto-Krestchmann set-up (see Figure 1.2). 


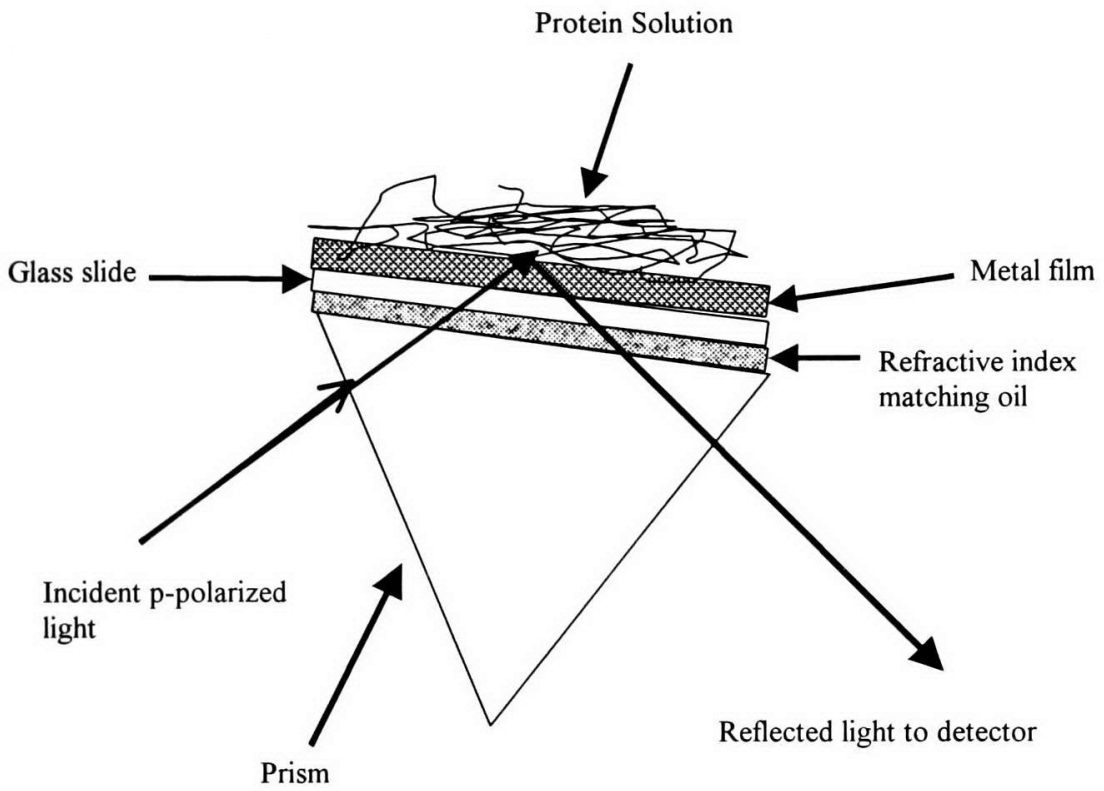

Figure 1.2 Otto-Kretschmann Prism Arrangement 
The Otto-Kretschmann prism arrangement is essentially a mechanism whereby a light ray is coupled into the surface plasmon (SP) mode that can exist on a metal film. Thin conductive films are commonly used to support the SP. Gold or silver films are most often used due to their relative ease with which they can be deposited onto a substrate with an accurate thickness. The surface chemistry of gold and its resistance to oxidation make it the prime choice for SPR experiments. The main criteria for a material to support SP waves are that it has a negative real dielectric constant. The thin film that will be used for support of the SP will be surrounded on both sides by a dielectric material (Figure 1.3). The SP can exist at the metal-dielectric interface within which it is possible to have components of an external electric field, E; present in both media. The total internal reflection of the beam is detected with a photodetector while the incident angle is varied.

The light launched into the prism and coupled into the SP mode on the film is ppolarized with respect to the metal surface where the reflection takes place. Only ppolarized light can be coupled into the plasmon mode because this particular polarization has the electric field vector oscillating normal to the plane that contains the metal film. This is sometimes referred to as the transverse magnetic polarization

There are two types of surface waves: nonradiative and radiative ones. We will make use of nonradiative waves and for this specific radiation the dispersion relation is given by the following expression: 


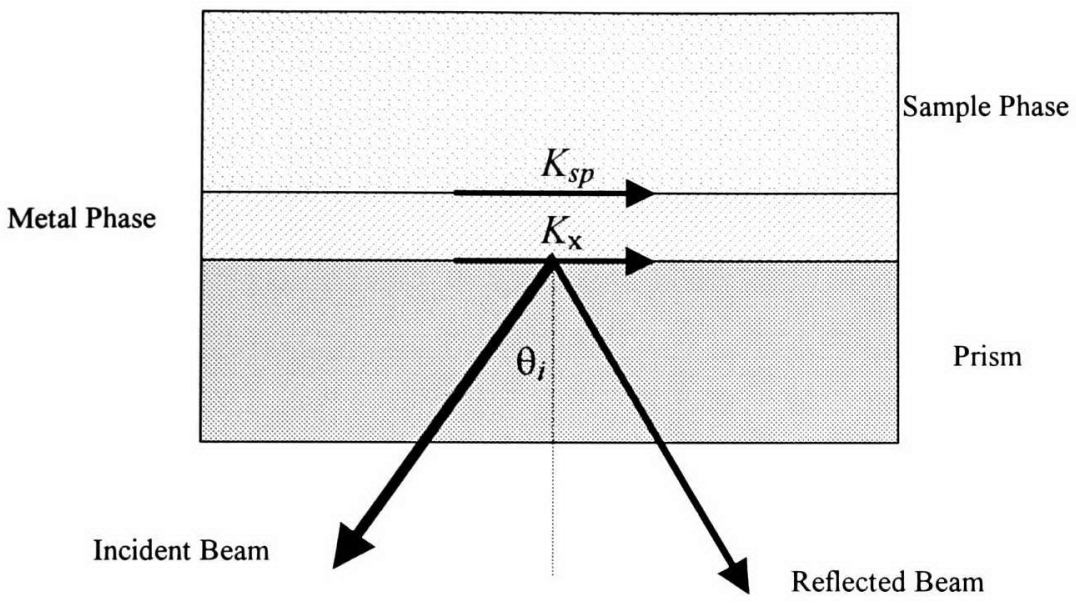

Figure 1.3 Graphical Representation of matching wavevectors at a given angle of incidence. 


$$
K_{0 s p}=\sqrt{\frac{\mathcal{E}_{1} \varepsilon_{0}}{\mathcal{E}_{1}+\varepsilon_{0}}}, \quad \text { where } \quad K_{0}=\frac{2 \pi}{\lambda}
$$

$\mathrm{K}_{0}$ is the wave vector of light in free space and $\lambda$ is the wavelength of the excitation light, $\varepsilon_{1}$ is the real part of the dielectric constant of the metal film and $\varepsilon_{0}$ is the dielectric constant for the medium outside the metal. The frequencies that are of interest are those at which $\boldsymbol{\varepsilon}_{1}$ is negative. If the excitation light is incident with an angle $\theta$, then the wave vector of the light incident on the surface is:

$K_{x}=\frac{2 \pi}{\lambda} n_{p} \sin \theta, \quad$ where $\quad \varepsilon_{p}=\sqrt{n_{p}}$

$n_{\mathrm{p}}$ is the refractive index of the prism. It must be noted that the dielectric constant is the square root of the refractive index. Figure 1.3 shows a schematic representation of the wave vector matching with the above equations. For $\theta_{1}$ greater than the critical angle between the prism and the medium (index $n_{0}$ ) above the metal $K_{\mathrm{x}}>n_{0} K_{0}$, the radiation may tunnel through the metal film to couple to the surface plasmons on its external surface. By increasing the angle-of-incidence for a given wavelength, it is possible to couple $K_{\mathrm{x}}$ to $K_{\mathrm{sp}}$ the wave vector for a semi-infinite metal and dielectric. If an adlayer of

finite thickness (d) of a surfactant, DNA, or protein is added to the system then $K_{\mathrm{sp}}$ should tend to: 


$$
K_{1 s p}=K_{0} \sqrt{\frac{\varepsilon_{0} \varepsilon_{2}}{\varepsilon_{0}-\varepsilon_{2}}}
$$

Where $\varepsilon_{2}$ is the dielectric constant of the overlayer.

$$
K_{s p}=K_{0 s p}+K_{1 s p}
$$

Where the relation (1.4) gives the value for $K_{\text {osp }}$, then for finite $d$, the dispersion relation becomes[19] :

$$
K_{1 s p}=K_{0}\left(\frac{\varepsilon_{2}-\varepsilon_{1}}{\varepsilon_{2}}\right)\left(\frac{\varepsilon_{0} \varepsilon_{1}}{\varepsilon_{0}+\varepsilon_{1}}\right)^{2}\left(\frac{\varepsilon_{2}-\varepsilon_{0}}{\varepsilon_{1}-\varepsilon_{0}}\right) \times\left(-\varepsilon_{0} \varepsilon_{1}\right)^{-1 / 2}\left(\frac{2 \pi d}{\lambda}\right)
$$

Hence the wave vector of the surface plasmon is sensitive to the change in the dielectric constant $\varepsilon_{2}$ and the thickness of the adlayer, therefore to the adsorption of molecules on the surface of metal films.

\section{5) Purpose of this work}

The purpose of this work is to demonstrate the potential of SPR for a variety of biological research applications, from the kinetics of protein adsorption and protein conformation to the study of vaccine, virus and infectious disease. The commercial instruments, however, do not have the resolution for detecting small amounts of analytes or small conformational changes in the analytes. The setup developed in this project can be transferred to commercial companies or directly used by individual research labs. 


\section{CHAPTER II \\ EXPERIMENTAL}

\section{1) AFM experiment}

The AFM studies of DDAB and Cytochrome $c$ were performed with a Nanoscope IIIa multimode AFM (Digital Instruments Inc.) Commercial sharpened $\mathrm{Si}_{3} \mathrm{~N}_{4}$ tips attached to triangular cantilevers were used. The set point was adjusted to minimize the force between the tip and the sample in each experiment. The graphite substrate $(\mathrm{ZYH}$, Advanced Ceramics Co.) used during the experiment was cleaved and covered immediately with buffer solution to minimize contamination. In all experiments the cantilevers were forced to vibrate at $30 \mathrm{KHz}$ with amplitudes in the range of $50-150 \mathrm{mV}$

\section{2) Electrochemical cell}

To study the electron transfer of Cytochrome $c$ with cyclic voltammetry we have used an electrochemical cell. The working electrode is the graphite substrate We used a $0.25 \mathrm{~mm}$ silver wire, which was calibrated with respect to the $\mathrm{Ag} / \mathrm{AgCl}$ electrode, as a quasi-reference electrode and a $0.1 \mathrm{~mm}$ Pt wire as the counter electrode. Before each experiment the Teflon cell was immersed in chromic acid for two hours and rinsed very well with pure water. The cell was then cleaned with methanol, and dried with pure $\mathrm{N}_{2}$. The inner ring of the cell received a coating of Apiezon wax to avoid leakage. The electrodes were rinsed before each experiment. The measurements were carried out with a model $283 \mathrm{EG} \& \mathrm{G}$ potentiostat. 


\section{3) SPR set-up}

Figure 2.1 shows the schematic representation of an SPR set-up. The He Ne laser beam $(\lambda=632.8 \mathrm{~nm})$ is expanded by an objective lens then collimated and passed through two polarizing glasses, which can be rotated up to 360 degree to obtain any combination of $s$ or $p$ polarization. Collimation of the light beam ensures linear polarization, which is important for the maximization of plasmon excitation at the metal/sample interface. The p-polarized light that is apertured down to set the desired input cone dimension from the converging lens. The light propagates through the hemicylindrical prism in a converging angular distribution with a minimized spot size at the SPR layer/prism interface. Figure 1.2 in the previous chapter shows the metal/prism assembly. The interface was obtained by coating a high quality microscope slide with a thin gold film $(45 \mathrm{~nm})$, which was epitaxially grown in vacuum. The slide is fixed against a BK-7 prism using refractive index-matching oil. The coated microscope slides are inexpensive and disposable, thus avoiding problems of cleaning and recalibration. The angular intensity distribution of the reflected light is reconstructed on a 1024 element linear photodiode array detector. Reflection intensities were calculated as a ratio. The angular resolution of this set-up is in the order of $0.005^{\circ}$. 


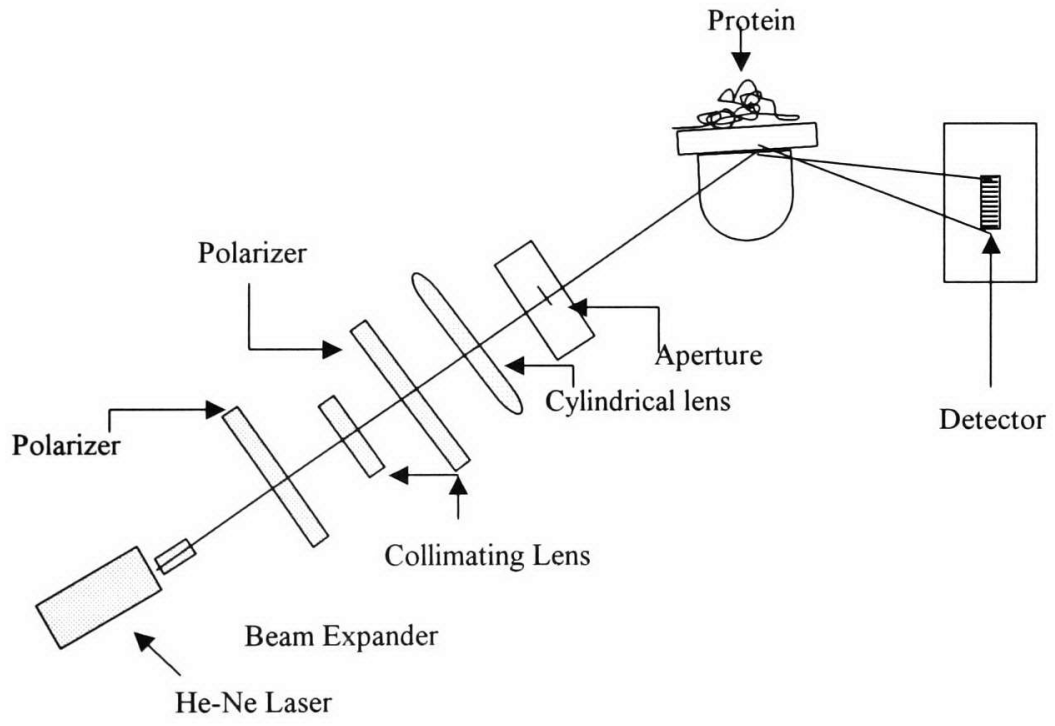

Figure 2.1 Schematic representation of SPR conventional set-up 
In a second homemade set-up, a $3 \mathrm{~mW}$-diode laser $(\lambda=670 \mathrm{~nm})$ is focused through a hemicylindrical prism onto a gold film mounted in the same way as in the previous setup (see Figure 2.2). On the gold film a Teflon cell with a port for purging with $\mathrm{N}_{2}$ is attached. Pt and $\mathrm{Ag}$ wires were used as counter and reference electrodes, respectively. The latter was calibrated with respect to a $\mathrm{Ag} / \mathrm{AgCl}$ reference electrode. Light reflected from the gold film is detected with a bi-cell photodiode detector, rather than the array detector. The ratio of the differential signal to the total signal is directly proportional to the shift of the resonant angle as shown by both theoretical simulations and experimental calibration. Because the set-up is compact, noise due to thermal drift and mechanical vibrations is greatly reduced. In contrast, high resolution in the conventional set-up requires a large distance between the array detector and the sample. The angular range is $3.2^{\circ}$ and the angular resolution on the order of $10^{-5} \circ$ for a bandwidth of $1 \mathrm{kHz}$. The estimated optimal resolution that can be within $10^{-8} \circ$ for the same bandwidth and angular range, so further improvements of the resolution are possible. The time response of the set-up is about few $\mu$ s and is limited by the preamplifier bandwidth, which also can be improved significantly. 


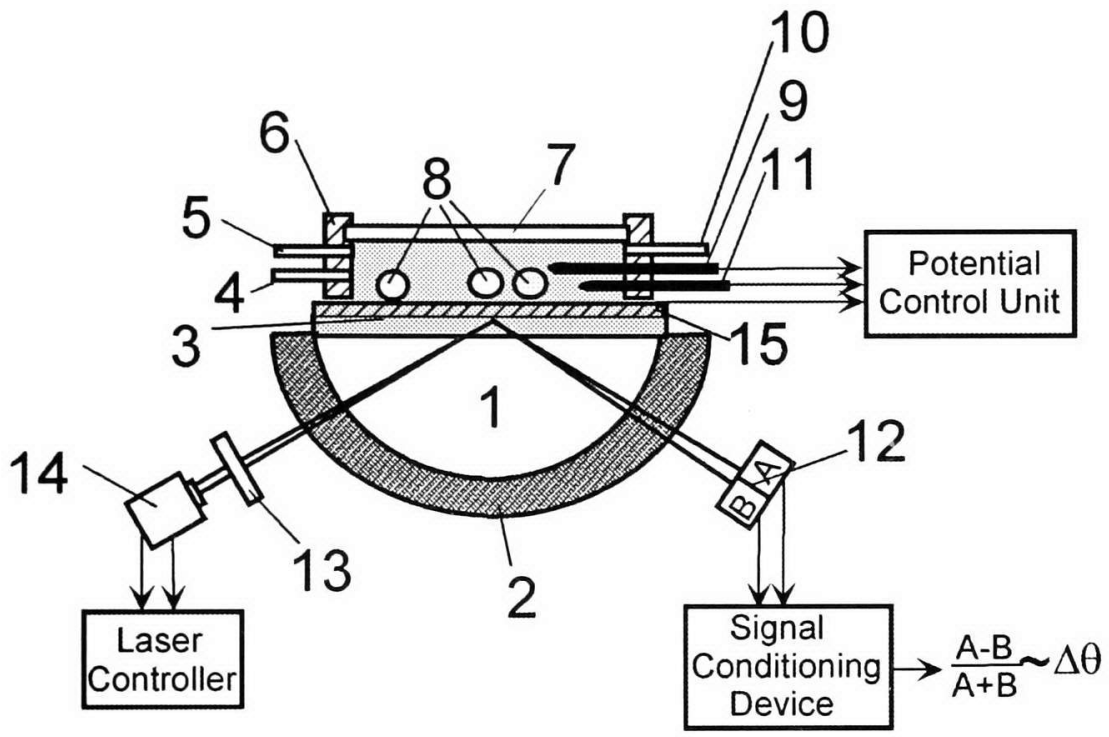

1. Prism. 2. Supporting frame. 3. Glass slide. 4. Solution port. 5. $\mathrm{N}_{2}$ port. 6. Solution cell. 7. Glass window. 8. Adsorbed molecules to be detected. 9. Counter electrode. 10. Solution port. 11. Reference electrode. 12. Bi-cell photodetector. 13. Lens. 14. Diode laser. 15. Metal film.

Figure. 2.2 Schematic Diagram of the High resolution SPR Set-up 


\section{4) Ultra High-Vacuum Thin Film Evaporator}

Thin gold films $\sim(45 \mathrm{~nm})$ were produced in the lab by vacuum deposition. Gold was grown epitaxially on microscope slides that were cleaned in chromic acid and rinsed with water then the slides were sonicated prior to evaporation in water and methanol for 30 min. The slides were dried with pure $\mathrm{N}_{2}$. The cleaned slides were attached to a $\mathrm{Cu}$ heating holder. The holder was then inserted in an ultra high-vacuum chamber over a Tungsten boat evaporator, in which gold spheres were placed $(99.999 \%$ from Johnson Matthew Catalog Company). Once sealed, the chamber was evacuated using a mechanical and a turbomolecular pump (Leybold). To evaporate possible water droplets, we heated the chamber to a temperature of approximately $130^{\circ} \mathrm{C}$. One hour after initiating the evacuation we started baking the slide substrates. The temperature of the holder was monitored through the use of a thermocouple attached to the holder. Usually after 3 hours of evacuation the pressure reaches $10^{-7}$ Torr.. We waited overnight and then degassed the gauging system and turned off the chamber heating system. About $60 \mathrm{~min}$. later we turned off the sample heater, and started the evaporation of gold

The evaporation was achieved through a large current applied to the Tungsten boat evaporator. We monitored the growth of the gold film with a thickness monitor (MAXTEK, inc. Model TM 100-R). The rate of deposition was set to $1 \AA / \mathrm{s}$ and the final thickness to $45 \mathrm{~nm}$. As soon as the evaporation was finished, the slides were baked, up to temperature of $300{ }^{\circ} \mathrm{C}$ for two hours. The samples were collected and placed individually in clean glass vials. These vials were stored in a low vacuum chamber under argon. Each time a gold film was collected from the low-vacuum chamber, Argon is 
alternated and evacuated in the chamber. The procedure was repeated three times to ensure a large percent of argon in the chamber.

\section{5) Materials.}

All solutions were prepared with Nanopure water from a Bioresearch Grade Purification System (Barnstread Co.) fed with campus deionized water. Tris- $\mathrm{HCl}$ and Horse heart Cytochrome $\mathrm{c}$ were purchased from Fluca Chemie AG. Horse heart Cytochrome $c$ was dissolved in $50 \mathrm{mM}$ phosphate buffer to a concentration of $150 \mu \mathrm{M}$. The protein was used without any further purification.

DDAB purchased from Sigma, and dissolved in chloroform (ACS reagent and HPLC grade, Sigma) to a concentration of $50 \mathrm{mM}$. Small unilamellar vesicles of DDAB were prepared according to the method described in [26]. In the first step of the preparation, $50 \mu \mathrm{L}, 500 \mu \mathrm{L}$, and $2.5 \mathrm{~mL}$ of the $\mathrm{DDAB}$ solutions were added to separate flasks of $50 \mathrm{~mL}$ Tris- $\mathrm{HCl}$ solution. Chloroform was then evaporated from the aqueous solutions by blowing $\mathrm{N}_{2}$ into the solution for 30 minutes, resulting in $0.1 \%, 1 \%$, and $5 \%$ $\mathrm{DDAB}$ solution $\mathrm{V} / \mathrm{V}$, respectively. In order to form uniform $\mathrm{DDAB}$ vesicles, the mixed solutions of $\mathrm{DDAB} /$ buffer were sonicated in an ice bath for approximately 45 minutes until the mixtures were a transparent color

The solutions for Self-Assembly Monolayers (SAM) were prepared with Mercaptopropionic acid (MPA), Cystamine dihydrochloride. $\left(\mathrm{S}_{2}\left(\mathrm{CH}_{2} \mathrm{CH}_{2} \mathrm{NH}_{2}\right)_{2} 2 \mathrm{HCl}\right)$ and 1-Dodecanethiol $\left(\mathrm{CH}_{3}-\left(\mathrm{CH}_{2}\right)_{11}-\mathrm{SH}\right)$. Different thiols were dissolved in water or ethanol to form solution of approximately $25 \mathrm{mM}$. 


\section{CHAPTER III}

\section{RESULTS AND DISCUSSION.}

\section{1) AFM study of DDAB layer on HOPG}

We started the experiment by imaging a freshly cleaved Highly Oriented Pyrolitic Graphite (HOPG) in Tris-HCl buffer. After a clear HOPG image was obtained (Figure 3.1), we introduced various amounts of DDAB solution into the AFM cell. Figure (3.2.a) is an AFM image of the surface in Tris- $\mathrm{HCl}$ buffer approximately one hour after injecting $25 \mu \mathrm{L}$ of $\mathrm{DDAB}$ vesicle solution into the cell. The image shows a DDAB layer selfassembled on the surface. The layer is rather uniform in thickness but contains many defects or pinholes. The thickness measured from the height profile is about $1.6 \mathrm{~nm}$ as is shown in Figure 3.2.b, corresponding to a monolayer of DDAB. Because the graphite surface is hydrophobic, the hydrophobic tails of the DDAB molecules likely face the surface while the hydrophilic heads of the molecule point to the water (Figure 3.2.c). We noted that the monolayer was very fragile and that imaging it in contact mode tended to destroy it easily.

We obtained multilayer $\mathrm{DDAB}$ films by increasing the concentration of $\mathrm{DDAB}$ vesicle solution in the AFM cell. In order to estimate the thickness of the film, we zoomed in on a small area and switched to contact from tapping mode. After repeatedly scanning the area under a large force in contact mode, we then switched back to tapping mode and zoomed out. The scanning tip swept off the DDAB molecules and created a square crater in the area. Figure 3.3.a is an AFM image obtained about 45 minutes after introducing $125 \mu \mathrm{L}(1 \% \mathrm{~V} / \mathrm{V})$ of $\mathrm{DDAB}$ vesicle solution into the sample cell. The square in the image outlined the tip-created crater. The depth of the crater is approximately $4.8 \mathrm{~nm}$ as 
we can see in the height profile in Figure.3.3.b, corresponding to a monolayer + a bilayer of DDAB (Figure 3.3.c).

This observation is consistent with a recent study of lipid vesicles on various electrodes with Quartz Crystal Microbalance (QCM) $[14,16]$ and SPR study, which found that the vesicles could spread on a hydrophobic surface and form monolayer and bilayer films

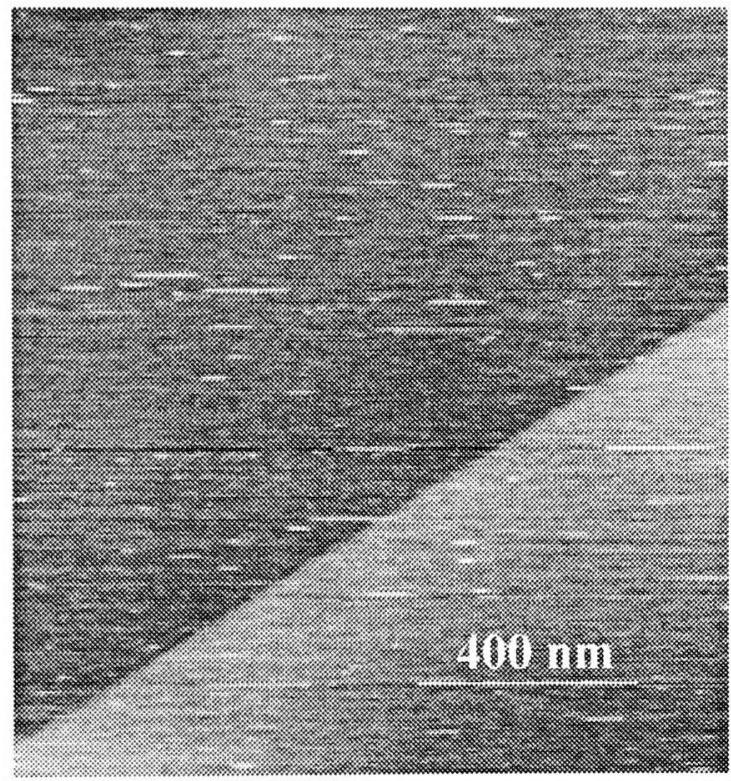

Figure 3.1 AFM Image of freshly cleaved HOPG surface in Tris-Hcl buffer 

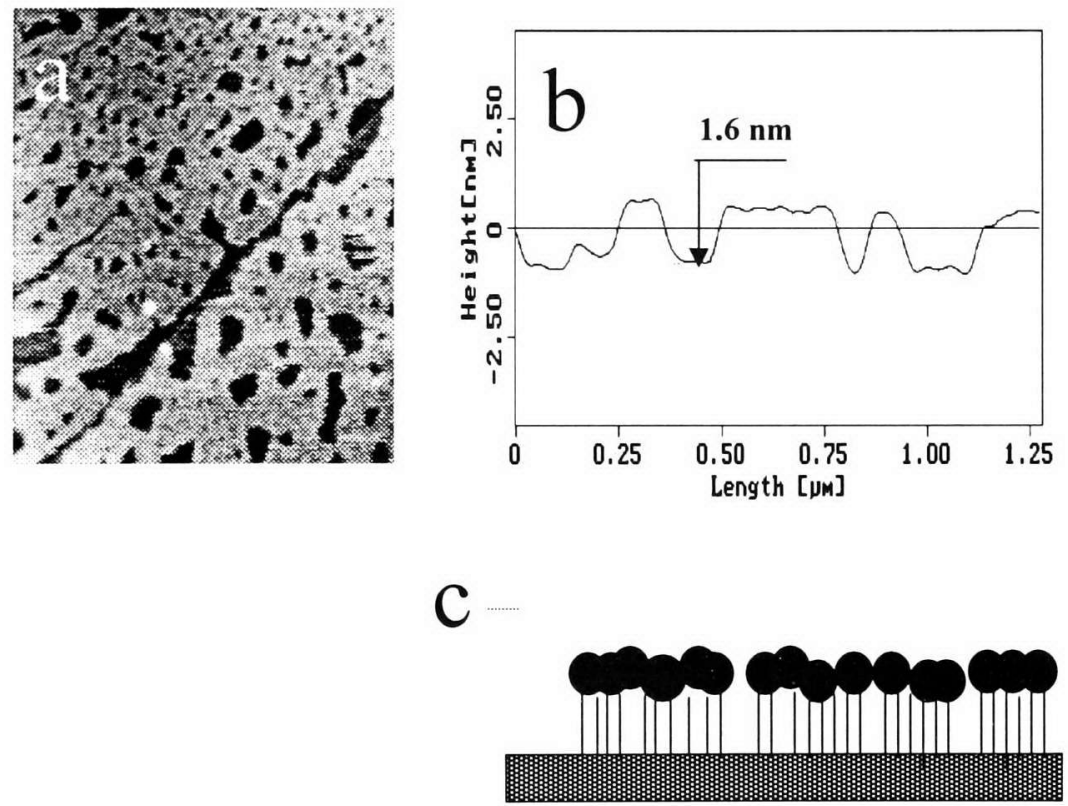

Figure. 3.2 Self-assemble DDAB monolayer on HOPG from DDAB vesicle solution. (a) Tapping-mode AFM image of the DDAB monolayer in Tris buffer solution. (b) Height profile along the dashed line shown in (a). (c) A model of the DDAB layer that explains the observed images. 

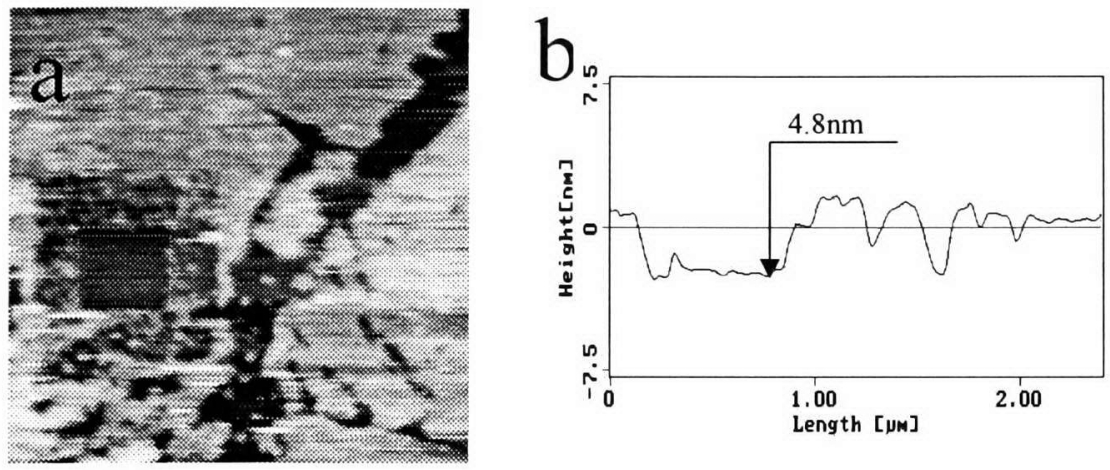

C

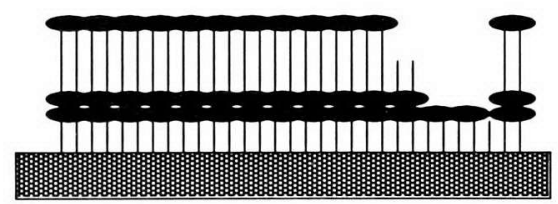

Figure 3.3 Self-assemble DDAB multilayer on $\mathrm{HOPG}$ from a DDAB vesicle solution.(a) Tapping-mode AFM image of the DDAB layer in Tris buffer solution, where the square outline the region where the $\mathrm{DDAB}$ molecules have been removed with the AFM tip. (b) Height profile along the dashed line shown in (a). (c) A model of the DDAB layer that explains the observed images. 


\section{2) SPR Study of the Adsorption of DDAB on Bare and Thiol-Coated SAM Gold}

\section{Surfaces.}

We examined the adsorption of DDAB onto bare gold and Self-assembled monolayers (SAM) of thiols using the convetional SPR setup described in the experimental chapter (see Figure 2.1). In this experiment a glass slide with a thin layer of gold $(45 \mathrm{~nm})$ is mounted as part of a Teflon cell . The excitation of surface plasmons is detected as a minimum in the intensity of reflected light at the resonance angle $\theta_{\text {res }}$ (Figure 3.4). In Figure 3.4 the resonant angle or SPR dip position changes over the time, which is represented by the two curves. The value of $\theta_{\text {sat }}$ depends on the dielectric constant of the interfacial region that is in contact with the gold, and on the thickness of an adsorbed layer of surfactant. We started the experiment by introducing a buffer solution $\left(50 \mathrm{mM}\right.$ Tris- $\left.\mathrm{HCl}, \mathrm{pH}=7.4, \mathrm{~T}=25^{\circ} \mathrm{C}\right)$ into the cell. The buffer solution is replaced with the DDAB vesicle solutions. First we introduced the solution with the smaller concentration $(0.1 \% \mathrm{DDAB} \mathrm{V} / \mathrm{V})$ when the $\mathrm{SPR}$ dip position reached the limiting value, the solution was replaced by buffer. This procedure was repeated with $1 \%$ and $5 \% \mathrm{~V} / \mathrm{V}$ concentracion of DDAB vesicle solutions. The value of $\theta_{\text {sat }}$ was recorded as a function of time. For thin films $(<100 \mathrm{~nm})$ of refractive index 1.45, the dependence of $\Delta \theta_{\text {sat }}=\theta_{\text {sat }}-\theta_{\mathrm{br}^{-}}$ as a function of $d_{\mathrm{sat}}$ is linear, where $\theta_{\mathrm{br}}$ is the value of initial resonant angle for buffer solution. The thickness of the surfactant layer is estimated by fitting the reflectivity plot versus angle of incidence for gold/buffer system. These data are fitted using Fresnel theory by varying the real and imaginary parts of the gold optical permittivity and the 
gold film thickness until the lowest sum of squares error is obtained. Once the angle of resonance reaches the limited value for DDAB vesicle the data are again fit using Fresnel theory. Using the gold parameters obtained from the previous fits and a priori knowledge of the index of refraction of DDAB $\left(\varepsilon_{2}\right)$ using equation (1.8), an average thickness for the surfactant overlayer is determined.

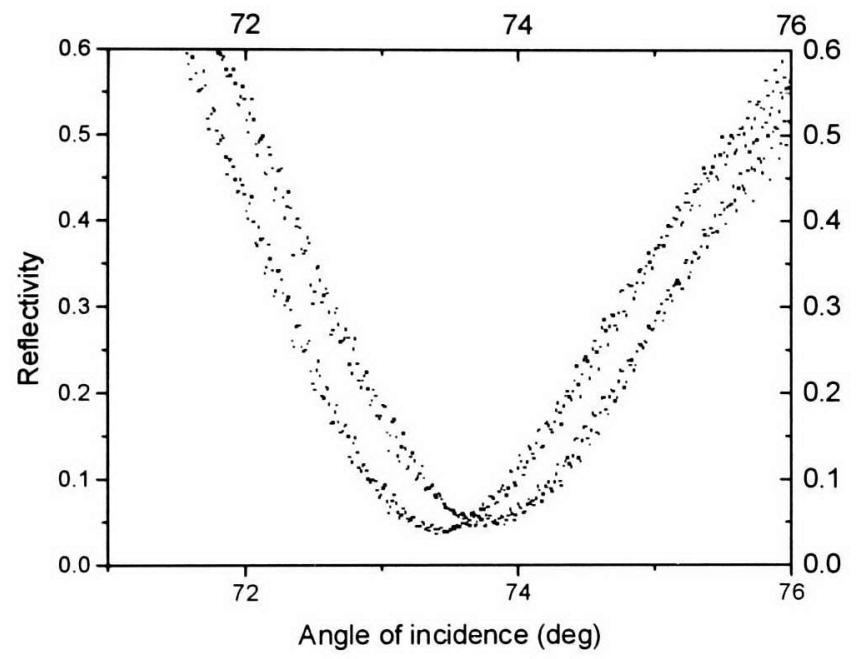

Figure 3.4. Reflectivity vs. Angle of incidence for bare gold exposed to DDAB solution. The two curves show the SPR dip position change over the time. 
The curve in Figures 3.5-8. a shows the change in $\theta_{\text {sat }}$ observed when buffer is allowed to flow through the cell, replaced with a solution of $\mathrm{DDAB}$, and then returned to buffer. The rise in $\theta_{\text {sat }}$ upon introduction of analyte to the cell is due principally to adsorption at the interface, and the fall in $\theta_{\text {sat }}$ is due to desorption. The signal due to analyte that adsorbs to the interface is the difference between the value of $\theta_{\text {sat }}$ for DDAB and initial resonant angle for buffer solution $\theta_{\text {buf }}$ The above protocol was used for all surfaces. Figure 3.5.a and table 3.5.b show the process of the adsorption of DDAB onto bare gold. It appears that $0.1 \% \mathrm{DDAB}$ solution forms very thin layer on a gold surface. The $\Delta \theta$ value in the presence of the DDAB solution is $\sim 0.25^{\circ}$. However, as soon as the DDAB solution is replaced with the buffer solution $\Delta \theta_{\text {sal }}$ drops to zero. This change can be attributed to the desorption of the monolayer inside the solution. As the concentration of the DDAB vesicle solution is increased, the $\Delta \theta_{\text {sat }}$ deep increased to $0.05^{\circ}$ for $1 \%$ and $0.5^{\circ}$ for $5 \% \mathrm{DDAB}$ vesicle solution. The latter reveals that the adsorbed layers of DDAB are more stable at high concentration than at low concentration. The final change in the resonant angle for $5 \%$ concentration of $\mathrm{DDAB}$ corresponds to an average thickness of 6 $\mathrm{nm}$, that is, a monolayer and 3 bilayers. The time needed for $\theta_{\text {sat }}$ to reach the limiting value decreases when we increase the concentration

The study of DDAB adsorption on thiol-modified gold is more interesting since the choice of the terminal group of the thiol molecule can allow us to control the process. In the case of 1-dodecanethiol the adsorption of DDAB is similar that of bare gold 
(Figure 3.6.a. and table 3.6.b).However, the total change is much smaller for both $1 \%$ and $5 \%$ solutions. The hydrophobic character of the $\mathrm{CH}_{3}$ terminal group may be the reason for this behavior. The small change of $\Delta \theta\left(0.25^{\circ}\right)$ may suggest that the adsorbed layers is thinner than in the conterpart on bare gold.

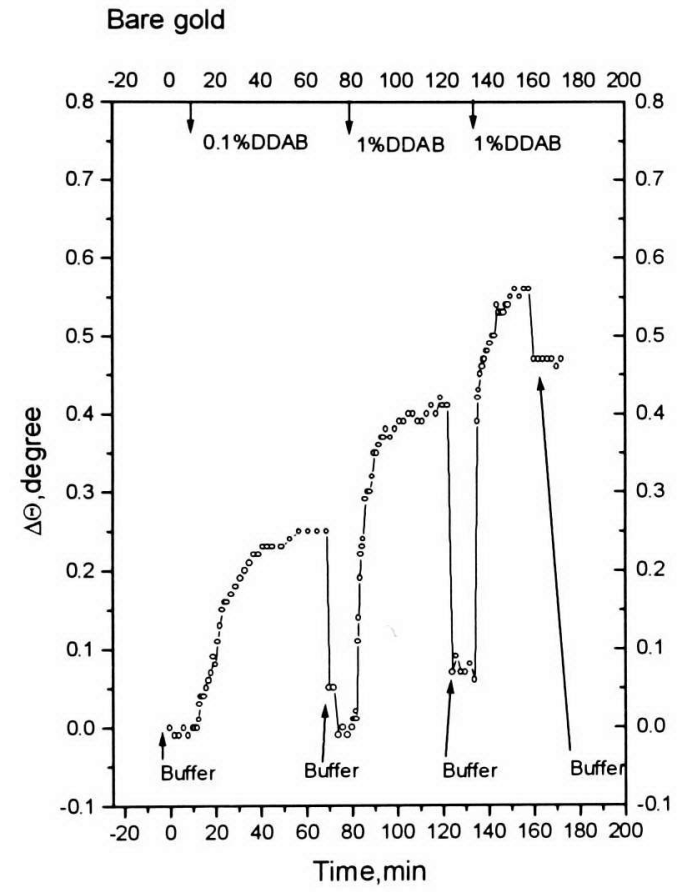

Table 3.5.b for bare gold

\begin{tabular}{|c|l|l|}
\hline Concentration & \multicolumn{1}{|c|}{$\Delta \theta_{\text {sat }}(\mathrm{deg})$} & $d(\mathrm{~nm})$ \\
\hline $0.1 \%$ & 0 & 0 \\
\hline $1 \%$ & 0.07 & 0.98 \\
\hline $5 \%$ & 6.6 & 6.6 \\
\hline
\end{tabular}

Figure 3.5. (a) Change of SPR position in angle vs. time for the adsorption of DDAB onto gold.

Table 3.5 (b) Concentration, thickness, and angular shift for layers of DDAB. 
Gold/1- Dodecanethiol

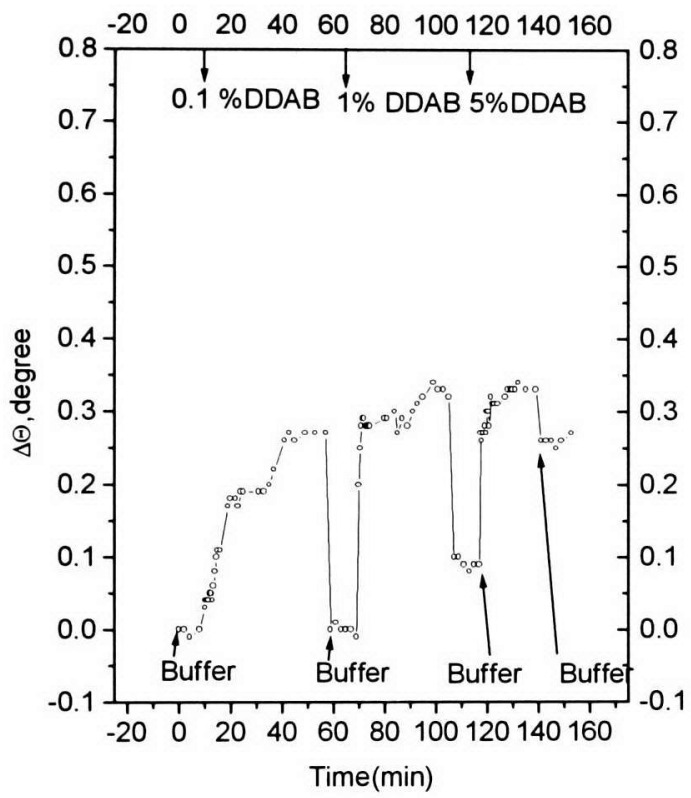

Table 3.6.b

\begin{tabular}{|l|l|l|}
\hline concentration & \multicolumn{1}{|c|}{$\Delta \theta_{\text {sat }}(\mathrm{deg})$} & \multicolumn{1}{c|}{$d(\mathrm{~nm})$} \\
\hline $0.1 \%$ & 0 & 0 \\
\hline $1 \%$ & 0.08 & 1.12 \\
\hline $5 \%$ & 0.25 & 3.5 \\
\hline
\end{tabular}

Figure 3.6. (a) Change of SPR position in angle vs. time for the adsorption of DDAB onto gold/ 1-dodecanethiol.

Table 3.6 (b) concentration, thickness, and angular shift for layers of DDAB on Au/ 1dodecanethiol. 
The adsorption of DDAB on Cystamine dihydrochloride is weak since the head of the DDAB is repeled by the positively charged groups of the monolayer (Figure 3.7. a and table 3.7.b). This electrostatic repulsion may cause changes to DDAB vesicle while in solution. It is possible that the DDAB layer on the surface in the presence of the vesicle solution is formed by DDAB micelles or vesicles.

In contrast to the previous SAM layer, Mercaptopropionic acid (MPA) is the only thiol that allows the adsorption of DDAB on the surface at 0.1 concentration as it is shown in Figure 3.8.a. and table 3.8.b. The total change of $\Delta \theta_{\text {sat }}$ jumps to $0.20^{\circ}$ for both $1 \%$ and $5 \%$ solutions. This suggests that the DDAB layer is at least a bilayer since the estimated $(d)$ adsorbed thickness is twice that of the monolayer. Also, the adsorbed layers are more stable than on the other SAM-coated gold films. We believe that the negative charge of the $\mathrm{COOH}$ terminal group of the MPA molecules attract the positively charged hydrophillic head group of DDAB moleculee, which is disolved in Tris- $\mathrm{HCl}$ (at $\mathrm{pH}=7$ ) and result in the formation of at least a bilayer. The formation of a single monolayer may not be posible since the hydrophobic tails are not stable in aquous phase. 
Au/Cystamine Dihydrochloride

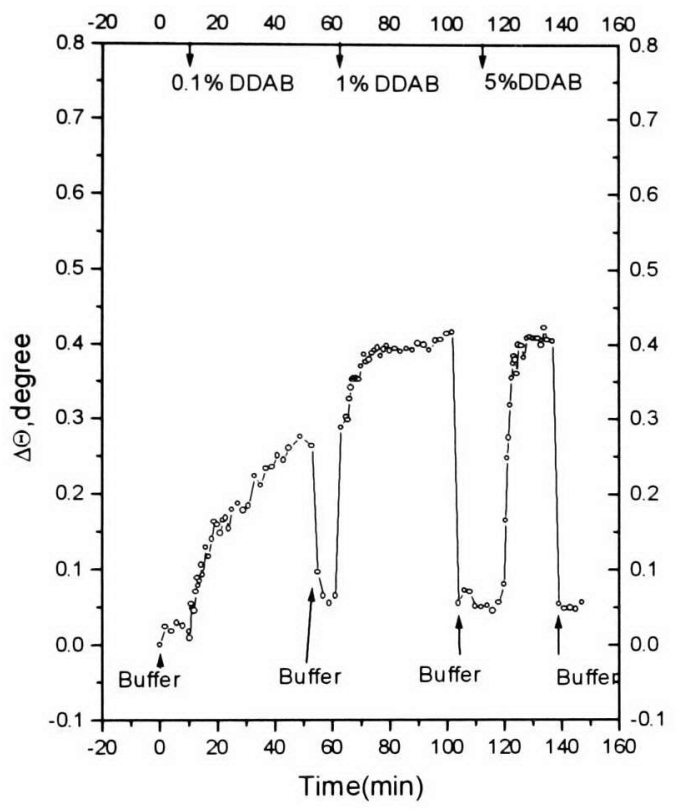

Table 3.7. b

\begin{tabular}{|l|l|l|}
\hline concentration & \multicolumn{1}{|c|}{$\Delta \theta_{\text {sat }}(\operatorname{deg})$} & \multicolumn{1}{|c|}{$d(\mathrm{~nm})$} \\
\hline $0.1 \%$ & 0.30 & N/A \\
\hline $1 \%$ & 0.30 & N/A \\
\hline $5 \%$ & 0.30 & N/A
\end{tabular}

Figure 3.7. (a) Change of SPR position in angle vs. time for the adsorption of DDAB onto gold/ cystamine dihydrochloride.

Table 3.7 (b) concentration, thickness, and angular shift for layers of DDAB on $\mathrm{Au} /$ cystamine dihydrochloride 


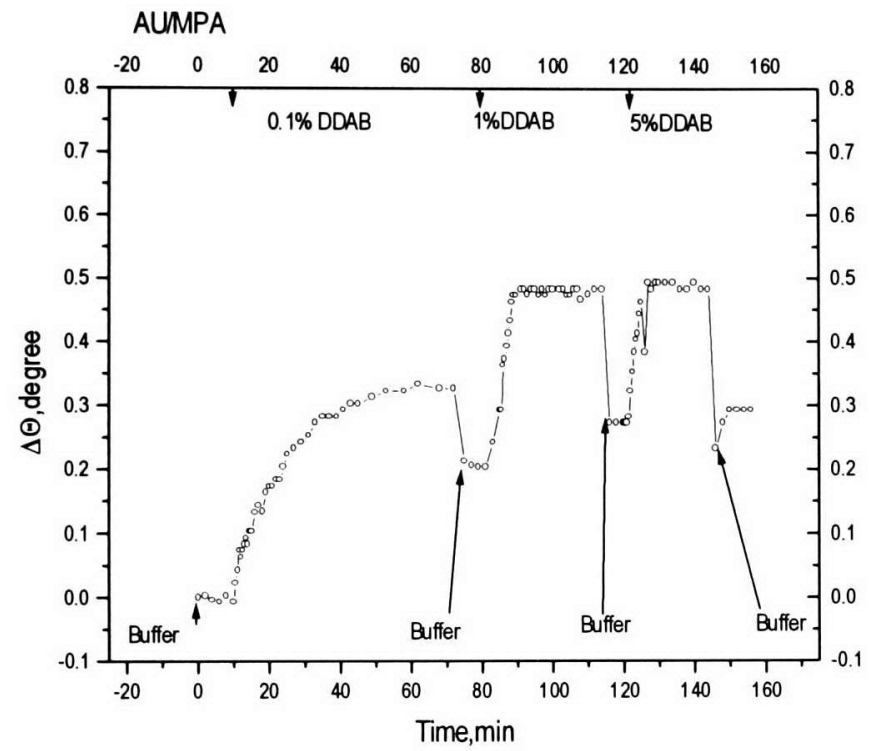

Table 3.8. b

\begin{tabular}{|l|l|l|}
\hline concentration & \multicolumn{1}{|c|}{$\Delta \theta_{\text {sat }}(\mathrm{deg})$} & $d(\mathrm{~nm})$ \\
\hline $0.1 \%$ & 0.20 & 2.8 \\
\hline $1 \%$ & 0.25 & 3.5 \\
\hline $5 \%$ & 0.28 & 3.9 \\
\hline
\end{tabular}

Figure 3.8 (a) Change of SPR position in angle vs time for the adsorption of DDAB onto gold/ MPA.

Table 3.8 (b) concentration, thickness and angular shift for layers of DDAB on Au/MPA. 
3.3) Structural and Electron Transfer Properties of Cytochrome c Adsorbed on Graphite Electrode Studied by in situ tapping Mode AFM

\section{3.a) AFM study of adsorbed Cytochrome c monolayers}

We first filled the AFM fluid cell with a solution of Cytochrome $c$ and allowed it to rest for 5 minutes for the adsorption to take place. The adsorbed proteins are then examined with the AFM and the results are shown in Figure 3.9. The images shown in Figure 3.9.a and 3.9.b indicate that the protein does adsorb on graphite and form a rather uniform monolayer. The individual proteins are revealed as randomly distributed blobs of $20-30 \mathrm{~nm}$ in lateral direction and $3-5 \mathrm{~nm}$ in vertical direction. The lateral dimension is considerably greater than the X-ray crystallography dimension [25] due to the wellknown AFM tip broadening effect. If we approximate the protein with a sphere of diameter $\mathrm{D}$, then the broadened diameter due to the finite tip radius is $(2 \mathrm{DR})^{1 / 2}$, where $R$ is the radius of curvature of the tip. The AFM tips used in this study have a nominal radius of curvature in the range of $20-40 \mathrm{~nm}$ as determined by scanning $5 \mathrm{~nm}$ gold colloidal particles with the same tip. The corresponding broadened diameter is between $22-31 \mathrm{~nm}$, which agrees with the observed values reasonably well.

We have imaged the sample with a tapping mode AFM in air after thoroughly rinsing it with nanopure water and drying it with nitrogen gas. The images (Figure 3.9.cd) show that drying has significantly modified the Cytochrome $c$ monolayer. Instead of being continuous, the film contains pinholes of $20-80 \mathrm{~nm}$ in dimensions, resembling the surface of Langmuir-Blodgett monolayers deposited on solid substrates at a surface pressure far bellow the collapse pressure [28]. We believe that the pinholes are formed 
when the proteins attempt to pack more closely as the water between them is evaporated.

Zooming into the film, AFM can still reveal the individual proteins (Figure 3.9.d), suggesting that Cytochrome $c$ molecules retain the globular structure after drying out in air. However, no proteins were observed inside of the pinholes, which demonstrate that the Cytochrome $c$ indeed forms only a monolayer.

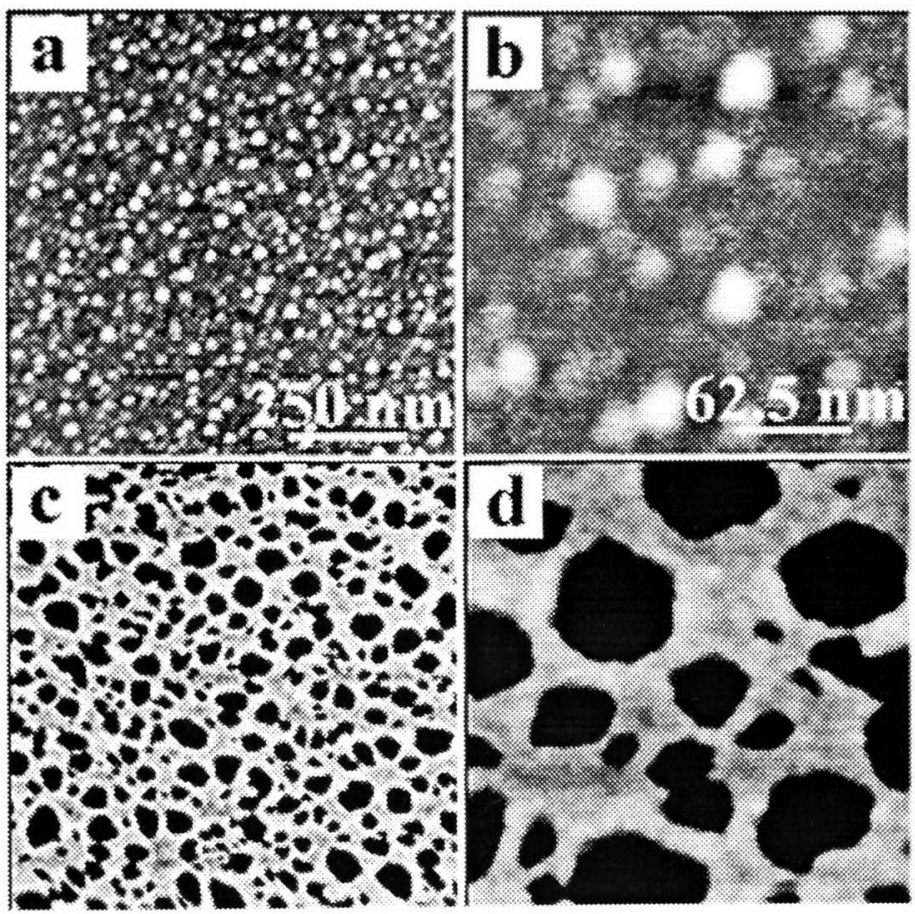

Figure 3.9 Tapping mode AFM images of Cyt $c(0.1 \mathrm{mM})$ adsorbed on graphite from $50 \mathrm{mM}$ phosphate buffer imaged in the buffer $(\mathrm{a}, \mathrm{b})$ and in air $(\mathrm{c}, \mathrm{d})$. 


\section{3.b) Real time monitoring Cytochrome $c$ adsorption}

We have studied the adsorption of Cytochrome $c$ on ZYH-grade highly oriented pyrolitic graphite (HOPG) in real time with AFM. We started the experiment by imaging a graphite substrate in phosphate buffer. Without stopping scanning, we introduced a drop of Cytochrome $c$ solution into the AFM cell and monitored changes on the surfaces continuously (Figure 3.10). Figure 3.10 a is a typical image of graphite in phosphate buffer captured before the introduction of Cytochrome $c$. The image is rather streaky which is due to weakly adsorbed phosphate. Increasing the potential, the streakiness decreased and the image became clear as stable phosphate layer was formed at positively charged substrate. The conclusion that streakiness is due to phosphate adsorption is further supported by the fact that we have always observed clear images of graphite when performing the same experiment in water or $\mathrm{NaClO} 4$ solution. We note that the adsorption of phosphate has been observed with contact mode AFM by Lindsay et al [29]. The Figure (3.10.b) captures the surface change during the introduction of Cytochrome $c$ into the buffer solution. The Cytochrome $c$ was introduced as the tip was scanning from bottom to the position marked with a line in the figure. Above the line the image shows the graphite surface covered with weakly adsorbed phosphate, similar to Figure (3.10.a). Bellow the line it shows a brief noisy region, corresponding to the disturbance caused by the introduction of the protein solution to the cell, then the region of adsorbed Cytochrome $c$. The adsorption of Cytochrome $c$ took place immediately after the introduction. We should mention that as soon as the protein adsorbed onto the 
surface, the streakiness in the image of graphite disappears. Figure 3.10.c shows the same area after the protein adsorption. The dimensions of the protein in this measurement

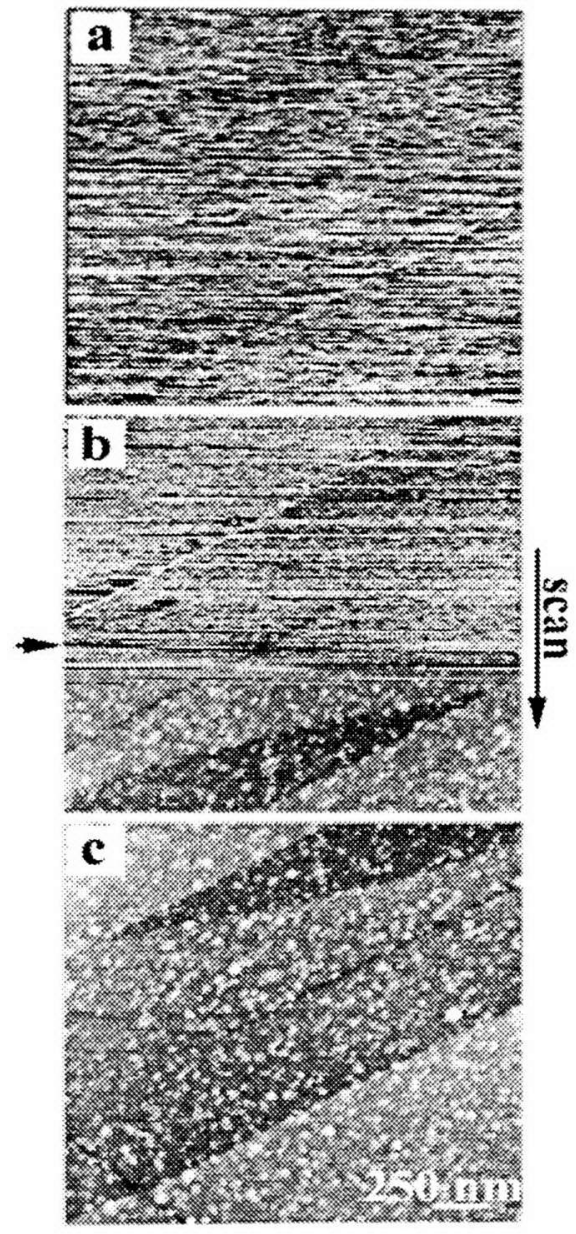

Figure 3.10. Tapping mode AFM images of graphite before (a), during (b) and after (c) a drop of $0.1 \mathrm{mM}$ Cyt $c$ into the sample cell containing $50 \mathrm{mM}$ phosphate buffer. 
are similar to those obtained when we directly expose the graphite substrate to Cytochrome $c$. However, the packing density of Cytochrome $c$ is lower due to the decrease in the concentration of Cytocrome $c$. This real-time measurement verifies that the blobs observed in the previous AFM images are due to the protein. It also shows that the formation of phosphate layer on the substrate is involved in the Cytochrome $c$ adsorption.

\section{3.c) Electron transfer reaction of adsorbed Cytochrome $c$.}

We have studied the electron transfer of Cytochrome $\mathrm{c}$ with cyclic voltammetry (CV). We started the experiment by measuring the current as the substrate potential is being cycled between 0.05 and $+0.35 \mathrm{~V}$ (Figure 3.11.a). We then gradually expand the potential range to $\pm 0.70 \mathrm{~V}$, and observed no sign of electron transfer within the potential window. However, when the upper limit of the potential is increased to $+0.75 \mathrm{~V}$ a pairs of peaks, corresponding to a reversible electron transfer, appeared (Figure 3.11.b). From the peak area we have determined the packing density of the adsorbed protein to be $2 \times 10^{12}$ proteins $/ \mathrm{cm}^{2}$, which is smaller than $3 \times 10^{12}$ protein $/ \mathrm{cm}^{2}$, the maximum density if assuming the proteins pack closely into a hexagonal lattice. This result is consistent with the coverage from the AFM images. The peak separation is about $0.03 \mathrm{~V}$ at $0.02 \mathrm{~V} / \mathrm{s}$, which increased gradually to $0.05 \mathrm{~V}$ at $2 \mathrm{~V} / \mathrm{s}$. This allows us to estimate the electron transfer rate to be $60-80 \mathrm{~s}^{-1}$, which is in good agreement with the value for Cytochrome $c$ on gold modified with 4-bpy [30]. The redox potential is about $0.17 \mathrm{~V}(\mathrm{Ag} / \mathrm{AgCl})$, somewhat more positive than the value of $0.035 \mathrm{~V}$ for Cytochrome $c$ in solution. This potential shift may be attributed to charge either in the local environment or in the 

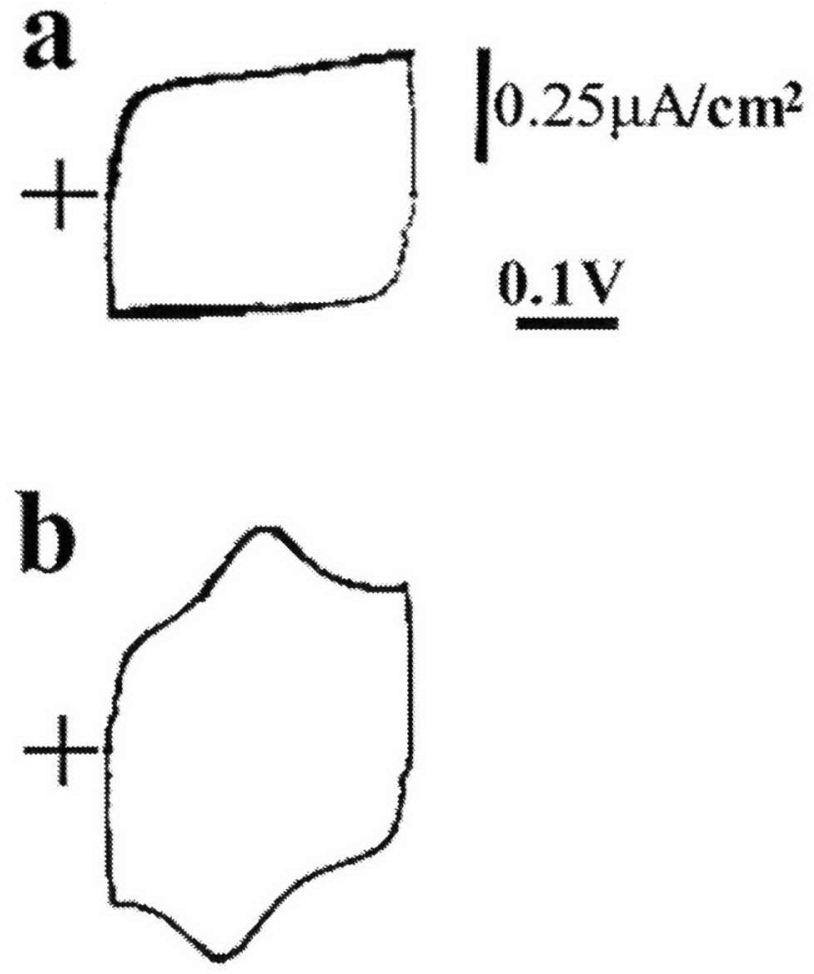

Figure 3.11. Cyclic voltammograms of graphite electrode in $0.1 \mathrm{mM}$ Cyt $c+50 \mathrm{mM}$ phosphate buffer recorded before (a) and after (b) cycling the potential to $0.75 \mathrm{~V}$.

conformation of the protein when it adsorbs on the electrode. In order to understand what causes the appearance of the redox activity as the potential is increased to $0.75 \mathrm{~V}$, we 
have monitored possible structural changes in the adsorbed protein with the AFM as a function of the potential. Figure 3.12.a is an AFM image obtained at $0.15 \mathrm{~V}$, which shows the individual proteins as in the previous images. Cycling the potential to $0.75 \mathrm{~V}$ then back to $0.15 \mathrm{~V}$ results in no change to the position and shape of each individual protein (Figure 3.12.b). We have also held the potential at $0.75 \mathrm{~V}$, and still found no visible changes in the adsorbed proteins (Figure 3.12 c). This result shows that Cytochrome $c$ retains its globular shape at $0.75 \mathrm{~V}$. We suggest that increasing the potential to $0.75 \mathrm{~V}$ does not significantly change the protein native conformation, but it causes the protein to reorient its redox center (heme group) to the substrate, therefore increasing the electron transfer probability. The reorientation occurs because the positively charged lysine residues are attracted by the negatively charged-phosphate layer adsorbed onto graphite. This hypothesis is supported by the following evidence:

Denaturation of Cytochrome $c$ has been found to result in large amount negative shifts in the redox potential which is not observed in this experiment. (2) The measured electron transfer rate is similar to that of Cytochrome $c$ on gold electrodes modified with the organic monolayer that are known to prevent its denaturation. (3) Our AFM images of graphite and gold in phosphate buffer shows that the phosphate anions adsorb and form stable layers at high potentials. Finally, we have examined possible structural differences between the oxidized and reduced forms of the protein and found no visible changes in the adsorbed protein. This observation is consistent with previous X-ray crystallography and NMR studies, which have reported very small structural differences between the oxidized and reduced states of Cytochrome $c$ [31]. 


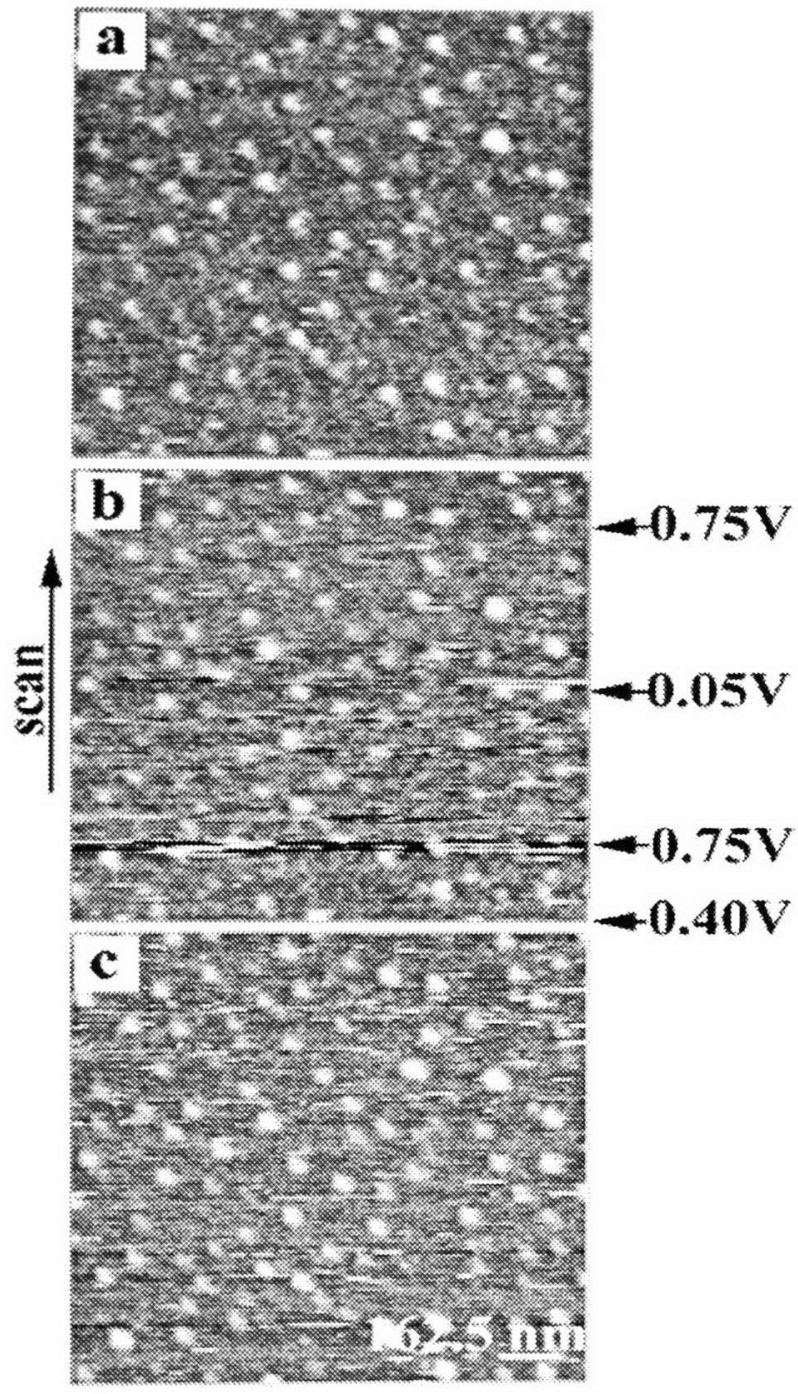

Figure 3.12. Tapping mode AFM images of adsorbed Cyt $c$ at $0.15 \mathrm{~V}$ (a), during a potential cycle from $0.40 \rightarrow 0.75 \rightarrow 0.05 \rightarrow 0.75 \mathrm{~V}$. (b) and at $0.75 \mathrm{~V}$ (c). 


\section{4) Electron Transfer Induced Conformational Changes in Redox Proteins Using}

SPR.

We started the experiment with characterizing an MPA-coated gold electrode in

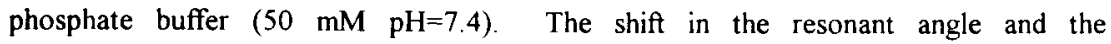
simultaneously recorded cyclic voltammogram (CV, inset) are shown in Figure 3.13.a. The shift in the dip over the potential window is about $0.003^{\circ}$. It has been recognized that electrode potential can change the SPR dip position via changing the electron density in the metal film [32]. The shift observed here is much smaller than that for a bare gold electrode. This is understandable because the presence of MPA decreases the interfacial capacitance therefore the electron density change for a given potential change. After characterizing the MPA-coated gold electrode in buffer, we then introduced $20 \mu \mathrm{L}$ of cytochrome $(270 \mu \mathrm{M})$ into the solution cell and monitored the change in the SPR dip position as a function of time (Figure 3.13 b). The dip position increased and reached a stable value in about 15 minutes. Replacing the protein solution with buffer solution, the dip position did not change much, which shows that once adsorbed onto the SAM, the adsorbed Cytochrome $c$ was rather stable on the surface $[33,34]$.

In the presence of adsorbed Cytochrome $c$, the $\mathrm{CV}$ exhibits a pair of peaks corresponding to the reduction and oxidation of the protein (Figure 3.13.c). From the peak area, we estimated the coverage of the adsorbed Cytochrome $c$ to be approximately $6 \times 10^{-12} / \mathrm{cm}^{2}$, which is close to a completed monolayer coverage. The simultaneously measured SPR dip position shows sigmoidal increases when we switch the state of the protein from the oxidized to reduced state. The change is reversible when switching the 

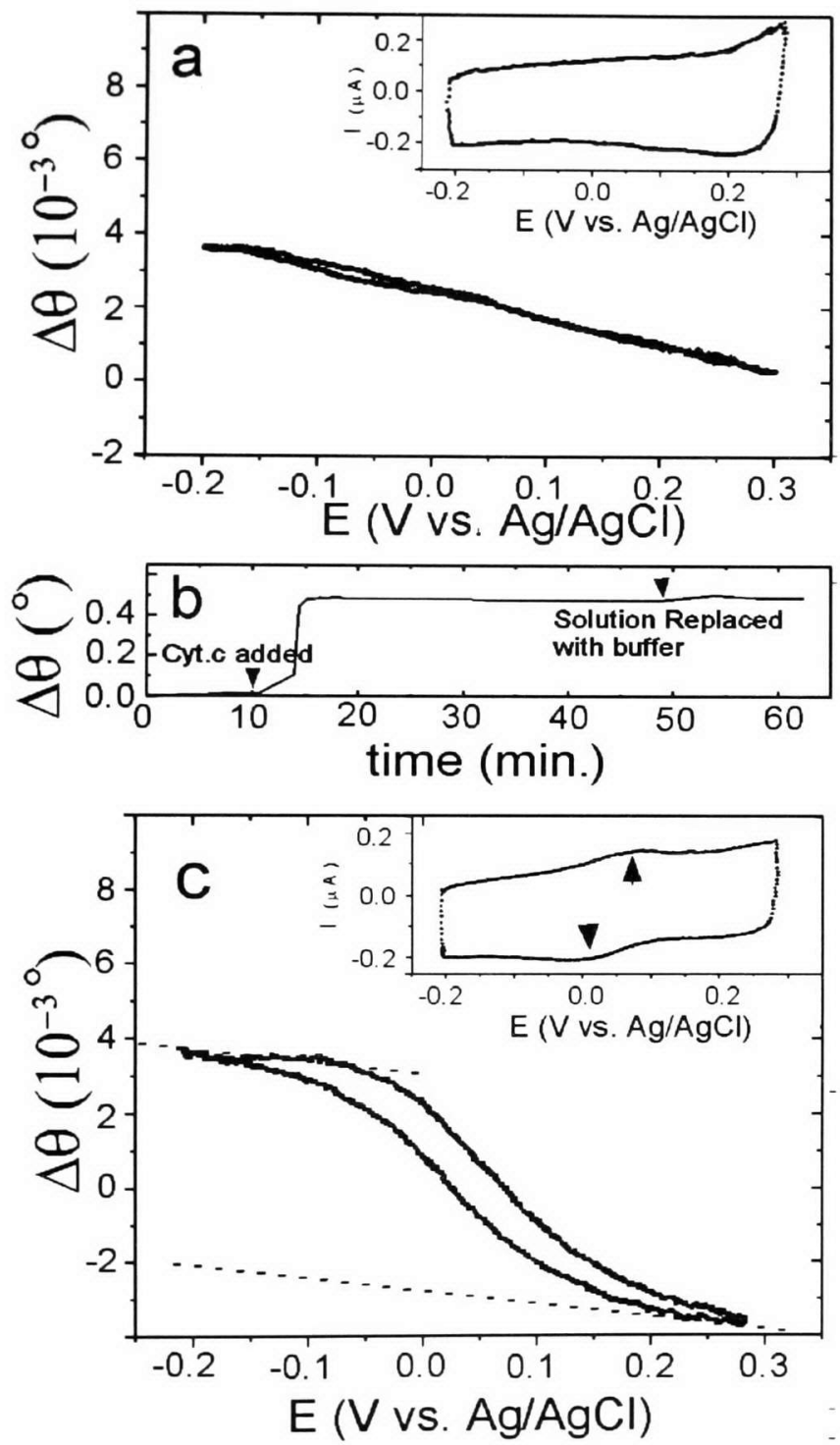

Figure 3.13. (a) SPR dip position and the simultaneously recorded cyclic voltammogram (cv, inset) for buffer. (b) Kinetics of adsorption of Cyt $c$ during the experiment. (c) SPR dip position and the simultanously recorded cyclic voltammogram (cv, inset) for Cyt $c$. 
protein back. Unlike the CV, the SPR dip position against potential plot depends little on the potential sweep rate. This is expected because SPR is sensitive to the overall electron transfer induced changes in the optical properties of the adsorbed protein. Before and after the large change near the redox potential, a small linear change in the dip is visible (dashed lines in Figure 3.13.c). This shift is believed to be a residual effect observed for the MPA-coated gold electrode in buffer solution. Subtracting this effect, the dip position change due to the electron transfer is about $0.006^{\circ}$. Note that the error in the change is primarily from the uncertainty in determining the background SPR shift, rather than from SPR dip.

The SPR shift can be attributed to a conformational change in the protein induced by the electron transfer reaction. This conformational change can alter both the thickness and the index of refraction of the protein layer. According to Lorentz-Lorentz relation [35], the change in the thickness $\Delta d$ can be calculated by $\Delta n / n=-(1 / 6)\left(1-1 / n^{2}\right)\left(2+n^{2}\right) \Delta d d$, where $n$ and $d$ are the index of refraction and thickness of the protein layer, respectively. Using the relation, we have estimated that $0.006^{\circ}$ increases in the dip angle as Cytochrome $c$ transforms from oxidized to reduced state corresponds to $\sim 0.2 \AA$ decreases in the thickness. This is consistent with studies by other techniques that cytochrome $c$ in the reduced state is more compact [8]. However, the change is rather small which does not support the hydrodynamic measurements but is in good agreement with $\mathrm{X}$-ray crystallography [36] and NMR studies [37].

We have followed the kinetics of the electron induced conformational change by taking the advantage of the fast response time of the present SPR setup. Figure 3.14.a 

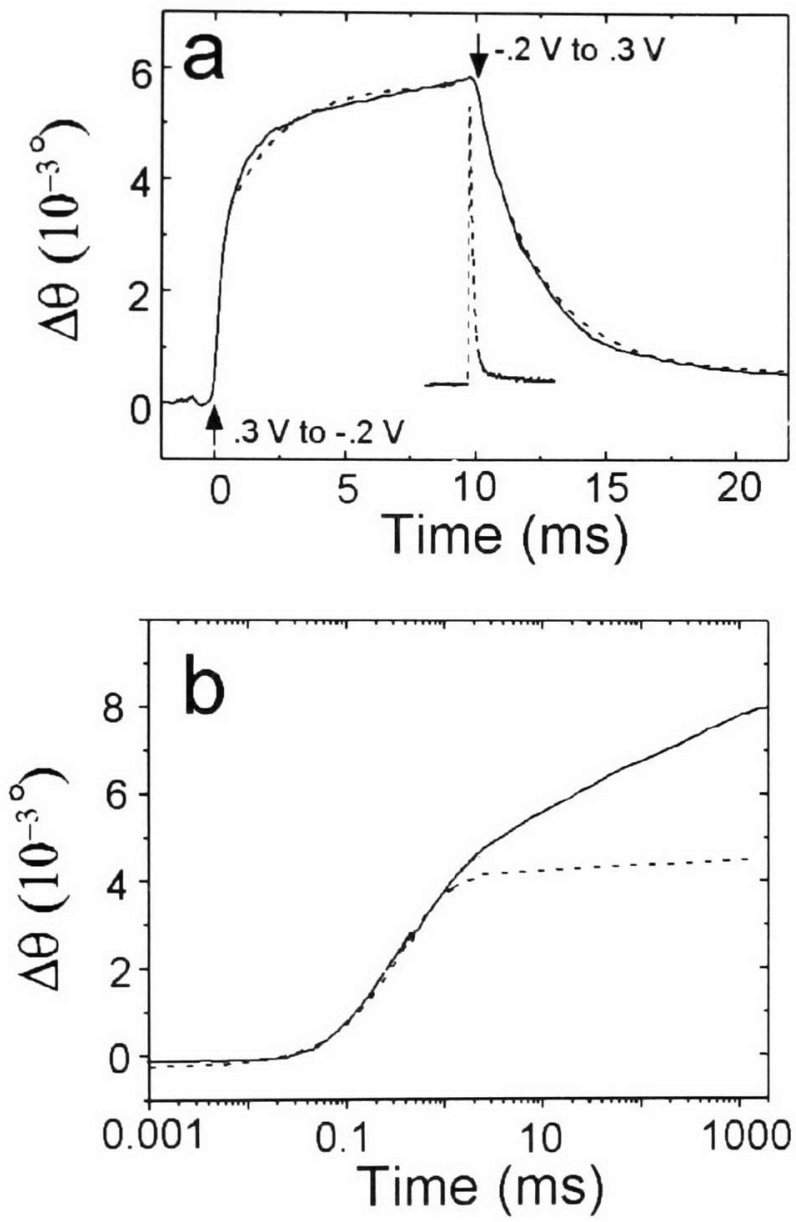

Figure 3.14. a) Kinetics of the electron transfer induced conformational change in Cytochrome $c$ immobilized on MPA-coated gold electrode in $50 \mathrm{mM}$ phosphate buffer. a) Response of the SPR dip position as the potential was stepped from $0.3 \mathrm{~V}$ to $-0.2 \mathrm{~V}$ and back to $0.3 \mathrm{~V}$ after staying at $-0.2 \mathrm{~V}$ for $10 \mathrm{~ms}$. The dashed lines are fitting with simple exp. function The inset: The current response during the potential stepping which illustrates the response time of the electrochemical cell b) SPR Response at the stepping time in the order of seconds. 
shows the response of the SPR dip position as the potential was suddenly stepped from $0.3 \mathrm{~V}$, where the protein was in the oxidized state, to $-0.2 \mathrm{~V}$, where the protein transfer into the reduced state. The potential was held at $-0.2 \mathrm{~V}$ for various intervals of time before being stepped back to $0.3 \mathrm{~V}$. The shortest time that can be studied is limited by the response time of the electrochemical cell, rather than by the SPR set-up, which has a response time of a few $\mu \mathrm{s}$. The current response due to the potential stepping is shown as dashed peak in Figure 3.14.a, which decays with a time constant of $150 \mu$ s. The SPR dip shift due to the conformational change in the protein is much slower. Over the time window shown in Figure 3.14.a, the SPR response can be roughly fitted by an exponential function with a time constant of $\sim 2.1 \mathrm{~ms}$ for the reduction and $\sim 2.5 \mathrm{~ms}$ for the oxidation. The change due to the reduction is faster than the oxidation. This observation is consistent with the previous studies that cytochrome $c$ in the reduced is more stable than that in the oxidized state [38]. A previous circular dichronism study has also shown that the transition from the reduced to the oxidized states is slower [39].

The above single exponential description of the conformational kinetics is not complete. Extending the time scale to the order of seconds, we found a long tail in the SPR kinetics that cannot be simply described by a simple exponential function (Figure 3.14.b). This long tail is slower than an exponential function and can be roughly fitted with a stretched exponential function, $\exp \left[-(\mathrm{t} / \tau)^{\beta}\right]$, with $\beta \sim 0.3$ and $\tau \sim 0.3 \mathrm{~s}$. We note that stretched exponential decays have been reported in liquid-glass transitions and in the kinetics of myoglobin [40]. This slow nonexponential decay is likely due to a slow rearrangement of the protein on the MPA layer after being switched to a new state. 
Further study is clearly needed for a complete understanding of this interesting slow relaxation process. 


\section{CHAPTER IV}

\section{CONCLUSIONS}

Membrane-like structures formed by surfactant molecules of DDAB on HOPG were studied with AFM. The studies show that the thickness of the adsorbed layer of DDAB is strongly dependent on the concentration of the DDAB vesicle solution.

The application of SPR spectroscopy to the measurement of thin adsorbed layers on both, bare and thiol-coated gold electrodes has been demonstrated. The formation of the layers was monitored in situ and in real-time. Complementary data were acquired by angle-dependent reflectivity measurements. Layer thickness of the adsorbed DDAB films on gold were determined using SPR and found to be in close agreement with those obtained from AFM measurements.

We have studied the adsorption of Cytochrome $c$ on HOPG from phosphate buffer by in situ tapping mode AFM. The real-time AFM study reveals that the protein adsorbs spontaneously on the surface and forms a uniform monolayer. The adsorbed protein does not undergo the well-known $\mathrm{Fe}^{3+} \leftrightarrow \mathrm{Fe}^{2+}$ electron transfer. However, midpoint redox potential takes place at $0.17 \mathrm{~V}(\mathrm{Ag} / \mathrm{AgCl})$, once the electrode potential is cycled to +0.75 V. Before introducing Cytochrome $c$ into the sample cell, we have observed that phosphate adsorbed onto graphite and formed a stable layer at high potentials

We have used a high resolution SPR spectroscopy to study subtle conformational change due to the electron transfer reaction in Cytochrome $c$ immobilized on MPAcoated electrode. The electron transfer induced change in the resonant angle is about $0.006 \mathrm{deg}$. Increase in the resonant angle as Cytochrome $c$ transforms from oxidized to 
reduced state corresponds to $\sim 0.2 \AA$ decreases in the thickness. This shows that Cytochrome $c$ in the reduced form is more compact than in the oxidized form.

Surface Plasmon Resonance has emerged as a powerful technique for a variety of biological applications, such as protein engineering, receptor-ligand interactions, monoclonal antibody characterization. The technique detects the resonance of collective oscillations of electrons, or the so-called surface plasmons, in a metal film with light. Because the resonant condition is extremely sensitive to the optical properties of the medium adjacent to the film, presence of biomolecules on the film can be detected. The achieved sensitivity is already impressive, but for many applications it is vital to further improve the system. I suggest to develop a SPR with the capability of directly measuring the electronic states of the molecules. The new capability will provide not only new insights into the conformational and electronic changes in the molecules but also direct identification of the molecules. For probing the electronic states of molecules, the resonant angle shift is measured as a function of the incident light wavelength. 


\section{REFERENCES}

[I]. Milan Mrksich, George B. Sigal, and George M. Whitesides, Langmuir 1995, 11, 4383- 4385 .

[2]. Michael Grunze, Fabien Josse, Milan Mrksich and George M. Whitesides, Anal. Chem. 1997, 69, 3321-3328.

[3]. George B. Sigal, Milan Mrksich, and George M. Whitesides, J. Am. Chem. Soc. $1998,120,3464-3473$.

[4]. S.Boussad, N.J. Tao and R. Arechabaleta, Chemical physics letters (1987), 280, 397403.

[5]. Scott, R.A and Mauk,A.G., Cytochrome c: A Multidisciplinary Approach. 1995. University Science Books, Sausalito, California.

[6]. Margoliash, E. and Schejter, A. Adv. Protein Chem. 1996, 21, 113.

[7]. Chin, P. and Brody, S.S, Biochemistry. 1975, 14, 1190.

[8]. Eden,D., W.R., Matthew, J. B., Rosa, J.J. and Richards, F.M. Proc. Natl. Acad. Sci. USA, $1982,79,815$.

[9]. Fisher, W.R., Taniuchi, H. and Anfinsen, C.B. J.Biol. Chem. 1973, 248, 3188.

[10]. Trewhella, J., Carson, V.A.P., Curtis, E.H. and Heidon, D.B. Biochemistry. 1988, 27,1121 .

[11]. S. Boussad and N. J. Tao, J. Am. Chem. Soc., 1999, 121, No 18, 4513.

[12]. Brian L. Frey, Claire E. Jordan, Steven Kornguth, and Robert M Corn*, Anal. Chem. 1995, 67, 4452-4457.

[13]. Graham J. Leggett, Martyn C. Davies, David E. Jackson, and Saul J. B. Tendler, J. Phys. Chem. 1993, 97, 5348-5355.

[14]. Jeremy J. Ramsden. Rev. Biophys. Feb 1994, 27:(1), 41-105.

[15]. Aptel, J. D., Voegel, J. C. \& Schmitt, A., Colloidal Surf. 29, 359-371

[16]. Kanazawa, K. K. \& Gordon, J. G., , Analytica chim. Acta 1985, 175, 99-105. 
[17]. Bloomfield, V., Dalton, W. O. \& Holde, K. E., Biopolymers, 1967, 5, 135-148.

[18]. Prime, K. L.; Whitesides, G. M. J. Am. Chem. Soc. 1993, 115, 10714-10721.

[19]. Frank Caruso, Michael J. Jory, Geoffrey W. Bradberry, J. Roy Sambles, D. Neil Furlong. J. Appl. Phys. January 1998, 83 (2).

[20]. H. Raether, Physics of Thin Films, Academic Press: New York, 1977; 145-261.

[21]. D. Korwer., D. Schumacher, and A. Otto; Phys. Chem., 1991, 95, No. 11, 14841488.

[22]. R. I. Tucceri and D. Posadas; J. Electroanal. Chem., 1990, 283, 159-166.

[23]. C.F. Quate, Surface Science 299/300 (1994) 980-995.

[24]. M Cynthia Goh and Peter Markiewicz. Chemistry and Industry, 1992, 18, 687-691.

[25]. S. Boussaad, L. Dziri, R. Arechabaleta, N. J. Tao, and R. M. Leblanc; Langmuir $1998,14,6215-6219$

[26]. Keller, C. A. Kasemo, B. J. Biophys. 1998, 75, 1397-1402.

[27]. Rusling, J. and Nassar, A. E. F., J. Am. Chem. Soc. , 1993, 115, 11891-11897.

[28]. A.Tazi, S. Boussaad and R. M. Leblanc, Thin Solid Films. 1999, 353, 233-238.

[29]. S.M. Lindsay, N J. Tao, J A. DeRose, P.I Oden, R.E. Harrington, Y. Lyubchenko, Biophys. J. 1992, 61, 1570.

[30]. W.J. Albery, M.J. Eddowes, H.A.O. Hill, A.R. Hillman, J. Am. Chem. Soc., 1981, $103,3910$.

[31]. A. Schejter, in: Eds. R. A Scott, A.G. Mauk, Direct Electrochemistry of Cytochrome c in Cytochrome c (University Science Books, California, 1996) p. 335.

[32]. Kotz, R.; Kolb, D.M.; Sass, J.K. Surf. Sci. 1977, 69, 359-364.

[33]. Nahir, T.M., Clark, R.A.; Bowden, E.F. Anal. Chem., 1994, 66, 2595-2598

[34]. Z. Feng, S. Imabayashi, T. Kakiuchi, and K, Niki, J. Chem. Soc , Faraday Trans. $1997,93,1367-1371$.

[35]. Kittel, C. Solid State Phy'sics, John Wiley \& Sons, lnc., New York. 1996, pp390. 
[36].Takano, T. and Dickerson, R.E. 1981. J. Mol, Biol. 153, 79-115; Berghuis, A.M. and Brayer, G.D. 1992. J. Mol. Biol. 223, 959-976.

[37].Feng, Y., Roder, H. and Englander, S.W. Biochem. 29, 3494-3504.

[38].Moore, G.R.; Williams, R. J.Acc. Chem. Res. 1998, 31, 755-763.

[39]. Yuan, X.; Sun, S.; and Hawkridge, F.M., J. Am. Soc., 1990, 112, 5380-5381.

[40] Tian, W.D.; Sage, J.T.; Srajer, V.; Champion, P. M. Phys. Rev. Lett. 1992, 408-411 